\title{
Distribution of normalized critical current of bent multifilamentary Bi2223 composite tape
}

$\operatorname{AUTHOR}(\mathrm{S}):$

Ochiai, S.; Fujimoto, M.; Shin, J. K.; Okuda, H.; Oh, S. S.; Ha, D. W.

\section{CITATION:}

Ochiai, S....[et al]. Distribution of normalized critical current of bent multifilamentary Bi2223 composite tape. JOURNAL OF APPLIED PHYSICS 2009, 106(10): 103916.

\section{ISSUE DATE:}

2009-11

URL:

http://hdl.handle.net/2433/109906

\section{RIGHT:}

Copyright 2009 American Institute of Physics. This article may be downloaded for personal use only. Any other use requires prior permission of the author and the American Institute of Physics. The following article appeared in JOURNAL OF APPLIED PHYSICS 106, 103916 (2009) and may be found at http://link.aip.org/link/JAPIAU/v106/i10/p103916/s1 


\title{
Distribution of normalized critical current of bent multifilamentary Bi2223 composite tape
}

\author{
S. Ochiai, ${ }^{1, a)}$ M. Fujimoto, ${ }^{1}$ J. K. Shin, ${ }^{1}{ }^{H}$ H. Okuda, ${ }^{1}$ S. S. Oh, ${ }^{2}$ and D. W. $\mathrm{Ha}^{2}$ \\ ${ }^{1}$ Department of Materials Science and Engineering, Graduate School of Engineering, Kyoto University, \\ Sakyo-ku, Kyoto 606-8501, Japan \\ ${ }^{2}$ Korea Electrotechnology Research Institute, 28-1 Sungju-Dong, Changwon 641-120, South Korea
}

(Received 25 June 2009; accepted 5 October 2009; published online 23 November 2009)

\begin{abstract}
The distribution of the normalized critical transport current (critical current normalized with respect to the original value) of Bi2223/Ag/Ag alloy composite tape under bending strain of $0 \%-0.833 \%$ was studied experimentally and analytically. The experimental results were analyzed by a modeling approach based on the relation of the heterogeneous damage evolution to the distribution of the critical current. The main results are summarized as follows. (1) The measured distribution of the critical current values varying with bending strain was described well by the present approach. (2) When all specimens were damaged at high bending strains $(0.338 \%-0.833 \%$ in the present work), the distribution of the critical current of the bent-damaged specimens was expressed by the three-parameter Weibull distribution function, the reason for which was revealed. (3) The distribution of the irreversible strain was estimated, with which the influence of the increase in the fraction of damaged specimens on the variation of critical current distribution in the low bending strain range (0\%-0.35\%) was elucidated. (C) 2009 American Institute of Physics.
\end{abstract}

[doi:10.1063/1.3259400]

\section{INTRODUCTION}

Superconducting composite tapes are subjected to mechanical and electromagnetic stresses during fabrication, winding, and operation. ${ }^{1,2}$ When the stress is high, the composite tapes are damaged, resulting in loss of the superconducting properties. To realize a reliable and safe design, it is necessary to estimate the variation of the critical current distribution with bending strain, together with the distribution of irreversible bending strain.

Concerning the damage behavior under bending strain and its relation to the critical current in the multifilamentary Bi2223 composite tape, it is known that the critical current is reduced first at the irreversible strain $\varepsilon_{\mathrm{B} \text {,irr }}$ at which the damage to the Bi2223 filaments initiates, and then it decreases with increasing strain due to damage evolution. ${ }^{3-17}$ Under no applied strain, the critical current is different from specimen to specimen and from position to position within a specimen. ${ }^{18-24}$ Under applied strain, the damage evolution behavior is also different from specimen to specimen and from position to position within a specimen, resulting in wider distribution of critical current. ${ }^{12-17}$ It is necessary to find a suitable function for describing the critical current distribution of the bend-damaged specimens. The first aim of the present work is to find a suitable function and to account for its validity from a physical viewpoint.

As the damage initiation behavior is also different from specimen to specimen, the $\varepsilon_{\mathrm{B} \text {,irr }}$ values differ among the specimens. ${ }^{12}$ This indicates that when many specimens are tested under a given bending strain $\varepsilon_{\mathrm{B}}$, the specimens with $\varepsilon_{\mathrm{B}, \text { irr }}$ values higher than $\varepsilon_{\mathrm{B}}$ are not damaged and retain the original critical current, while the specimens with $\varepsilon_{\mathrm{B} \text {,irr }}$ val-

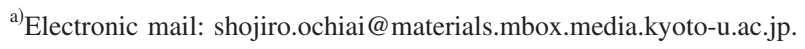

ues lower than $\varepsilon_{\mathrm{B}}$ are damaged and their critical current is reduced. Accordingly, the damaged and nondamaged specimens coexist when $\varepsilon_{\mathrm{B}}$ is in the range of distributed $\varepsilon_{\mathrm{B} \text {,irr }}$ values. The critical current distribution as a function of $\varepsilon_{\mathrm{B}}$ in such a range has, however, not yet been revealed. The second aim of the present work is to elucidate it.

\section{EXPERIMENTAL DETAILS}

The multifilamentary Bi2223/Ag/Ag alloy composite tape, fabricated at the Korea Electrotechnology Research Institute (KERI), was used in this research. It contained 55 Bi2223 filaments. The overall thickness $(t)$ and width $(W)$ of the sample were 0.23 and $4.1 \mathrm{~mm}$, respectively.

The critical current of bent samples was measured with the procedure employed in the round robin test of the Versailles Project on Advanced Materials and Standards/ Technical Working Area 16 (VAMAS/TWA 16) of superconducting materials. ${ }^{15}$ Bending strain $\varepsilon_{\mathrm{B}}$ (=tensile strain of the outer surface of the composite in the tensile side), expressed as $\varepsilon_{\mathrm{B}}=t /(2 R)$ where $R$ is the radius of the die, was applied at room temperature by pressing the specimen between an upper glass-fiber reinforced polymer die and a lower die with the same curvature. Six pairs of dies with radii $R=\infty$ (straight dies), 61.6, 34.0, 22.3, 17.3, and $13.8 \mathrm{~mm}$ were used to apply bending strain, corresponding to $\varepsilon_{\mathrm{B}}=0 \%, 0.187 \%, 0.338 \%$, $0.516 \%, 0.665 \%$, and $0.833 \%$ for the present tape. The specimens bent at room temperature were cooled to $77 \mathrm{~K}$, and the critical current $I_{\mathrm{c}}$ was measured with a criterion of $1 \mu \mathrm{V} / \mathrm{cm}$ in the self-magnetic field. The distance between the voltage taps was $10 \mathrm{~mm}$. After measurement of the critical current at a given bending strain, the specimens were warmed to room temperature and the bending strain was increased to the next value. The specimens under increased bending strain were 


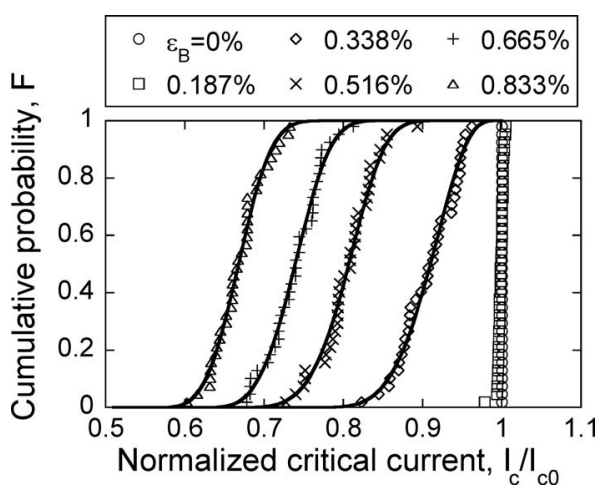

FIG. 1. Cumulative probability $(F)$ of the measured normalized critical current $\left(I_{\mathrm{c}} / I_{\mathrm{c} 0}\right)$ values at $\varepsilon_{\mathrm{B}}=0 \%, 0.187 \%, 0.338 \%, 0.516 \%, 0.665 \%$, and $0.833 \%$. The solid curves at $\varepsilon_{\mathrm{B}}=0.338 \%, 0.516 \%, 0.665 \%$, and $0.833 \%$ show curves calculated with model S-based equation (5) using the estimated distribution function of $\varepsilon_{\mathrm{f}}-\varepsilon_{\mathrm{r}}$ values at each bending strain.

again cooled to $77 \mathrm{~K}$ for measurement of critical current. This procedure was repeated to obtain the critical currentbending strain relation. In this process, the damage induced by bending took place only at room temperature.

The critical current $I_{\mathrm{c}}(1 \mu \mathrm{V} / \mathrm{cm}$ criterion)-bending strain $\varepsilon_{\mathrm{B}}$ was measured for 36 test specimens. The $I_{\mathrm{c}}$ value was normalized with respect to the original critical current at $\varepsilon_{\mathrm{B}}=0, I_{\mathrm{c} 0}$, for each test specimen. The experimental results of the normalized critical current $\left(I_{\mathrm{c}} / I_{\mathrm{c} 0}\right)$ values are presented in Sec. III. The experimental results are analyzed, as described in Sec. IV. The analyzed results pertaining to the first and second aims mentioned in Sec. I are discussed in Secs. V and VI, respectively.

\section{MEASURED CRITICAL CURRENT $\left(I_{\mathrm{C}} / I_{\mathrm{CO}}\right)$ VALUES}

The cumulative probability $F$ and probability density $f$ of the $I_{\mathrm{c}} / I_{\mathrm{c} 0}$ values measured at $\varepsilon_{\mathrm{B}}=0 \%, 0.187 \%, 0.338 \%$, $0.516 \%, 0.665 \%$, and $0.833 \%$ are shown in Figs. 1 and 2, respectively. The change in the measured coefficient of variation $(\mathrm{COV})$ of the $I_{\mathrm{c}} / I_{\mathrm{c} 0}$ values with bending strain $\varepsilon_{\mathrm{B}}$ is shown in Fig. 3. The $I_{\mathrm{c}} / I_{\mathrm{c} 0}$ values of the 36 specimens remained almost 1 (unity) at $\varepsilon_{\mathrm{B}}=0.187 \%$. At $\varepsilon_{\mathrm{B}}=0.338 \%$, the $I_{\mathrm{c}} / I_{\mathrm{c} 0}$ values of all tested specimens were less than unity (Figs. 1 and 2), indicating that all specimens had been damaged at $\varepsilon_{\mathrm{B}}=0.338 \%$. The average irreversible strain $\varepsilon_{\mathrm{B} \text {,irr,av }}$ of the present sample was estimated to be $0.243 \%$ as shown later in Sec. VI. The COV of the $I_{\mathrm{c}} / I_{\mathrm{c} 0}$ values increased largely in the bending strain range from $0.187 \%$ to $0.338 \%$, which includes the average irreversible bending strain $\varepsilon_{\mathrm{B}, \text { irr,av }}$.

\section{MODEL AND METHOD FOR ANALYZING DAMAGE EVOLUTION AND ITS INFLUENCE ON CRITICAL CURRENT DISTRIBUTION}

Figure 4(a) shows an optical micrograph of the transverse cross section of the tape. When the image is enlarged three times in the thickness direction, the shape of the core (the region in which Bi2223 filaments are bundled into Ag) can be clearly observed, as shown with the broken curve in
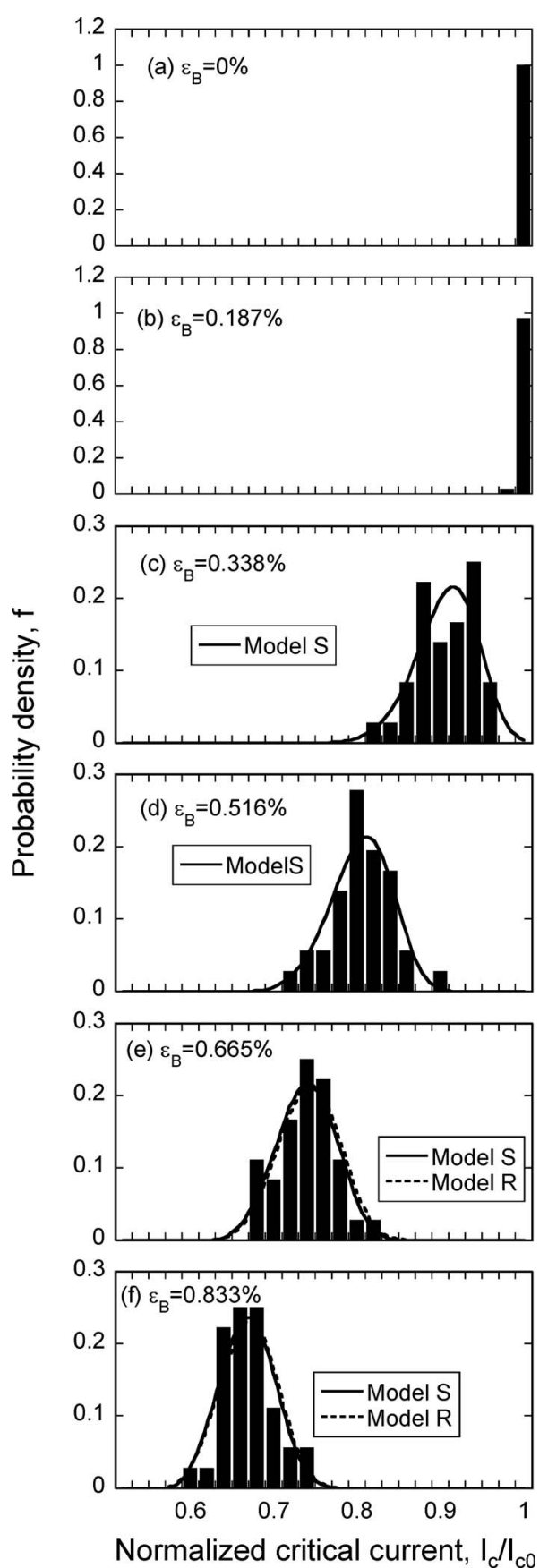

FIG. 2. Histogram of the measured normalized critical current $\left(I_{\mathrm{c}} / I_{\mathrm{c} 0}\right)$ values at $\varepsilon_{\mathrm{B}}=$ (a) $0 \%$, (b) $0.187 \%$, (c) $0.338 \%$, (d) $0.516 \%$, (e) $0.665 \%$, and (f) $0.833 \%$. The solid curves at $\varepsilon_{\mathrm{B}}=0.338 \%, 0.516 \%, 0.665 \%$, and $0.833 \%$ show curves calculated with model S-based equation (5) using the estimated distribution function of $\varepsilon_{\mathrm{f}}-\varepsilon_{\mathrm{r}}$ values at each bending strain. The broken curves at $\varepsilon_{\mathrm{B}}=0.665 \%$ and $0.833 \%$ show curves calculated with model R-based equation (8) using the estimated distribution function of $\varepsilon_{\mathrm{f}}-\varepsilon_{\mathrm{r}}$ values at each bending strain.

Fig. 4(b). As the damage to the Bi2223 filaments in the core causes the reduction in critical current, it is necessary to formulate its shape. We formulate the shape using two models, in a manner similar to our previous work. ${ }^{12}$ The first is referred to as model $\mathrm{S}$ in which the actual shape of the core is formulated, and the second is referred to as model $\mathrm{R}$ in which the shape of the core is approximated as a rectangle, as shown in Fig. 4(c). 


\section{A. Model S}

We took the directions corresponding to the width and thickness of the composite tape as $x$ and $y$, respectively, and the center of the composite tape as $x=y=0$ as shown in Fig. 4(c). Defining the $y$-coordinate of the core boundary (ABCDEFGHA) as $y_{\text {core }}$, we formulated $y_{\text {core }}$ as a function of $x$ with a ninth order polynomial, ${ }^{11}$ as follows. The length unit is millimeters.

CDE in Fig. 1: $\begin{aligned} & y_{\text {core }}= 0.0660214-0.0405173 x+1.03050 x^{2}-4.05239 x^{3} \\ &+8.94014 x^{4}-12.6431 x^{5}+11.3895 x^{6}-6.22952 x^{7} \\ &+1.87094 x^{8}-0.235769 x^{9} \text { for } 0 \leq x \leq 1.95 \\ & \text { ABC: symmetry with EDC with respect to } x=0\end{aligned}$
AHGFE: symmetry with ABCDE with respect to $y=0$

The current-transporting Bi2223 filaments in the core are damaged when the exerted tensile strain along the specimen length direction exceeds the damage strain $\varepsilon_{\mathrm{f}}-\varepsilon_{\mathrm{r}}\left(\varepsilon_{\mathrm{f}}\right.$ is the fracture strain under no residual strain and $\varepsilon_{\mathrm{r}}$ is the residual strain in the sample length direction). ${ }^{5,11,12}$ When the bending strain $\varepsilon_{\mathrm{B}}$ reaches the irreversible strain $\varepsilon_{\mathrm{B} \text {,irr }}$, the damage to reduce the critical current takes place first at the outermost filaments existing at the maximum value of $y_{\text {core }}$ [Eq. (1)], $y_{\text {core, } \max }(=0.101 \mathrm{~mm}$ in the present tape $)$. When the bending strain is raised from $\varepsilon_{\mathrm{B}, \text { irr }}$ to $\varepsilon_{\mathrm{B}, i}$ and then to $\varepsilon_{\mathrm{B}, i+1}$, the damage front $y_{\mathrm{f}}$ moves from $y_{\mathrm{core}, \max }$ to $y_{\mathrm{f}, i}$ and then to $y_{\mathrm{f}, i+1}$ [Fig. 4(c)]. The damage front $y_{\mathrm{f}}$ is expressed by the following equation: ${ }^{5,11,12}$

$$
y_{\mathrm{f}}=\frac{(t / 2)\left(\varepsilon_{\mathrm{f}}-\varepsilon_{\mathrm{r}}\right)}{\varepsilon_{\mathrm{B}}} .
$$

The first damage takes place at $y_{\mathrm{f}}=y_{\text {core, } \max }$ [Fig. 4(c)] at $\varepsilon_{\mathrm{B}}=\varepsilon_{\mathrm{B}, \text { irr }}$ as stated above. Substituting $y_{\mathrm{f}}=y_{\text {core, } \max }$ and $\varepsilon_{\mathrm{B}}$ $=\varepsilon_{\mathrm{B} \text {,irr }}$ into Eq. (2), we obtain the irreversible bending strain $\varepsilon_{\mathrm{B}, \text { irr }}$ in the following form:

$$
\varepsilon_{\mathrm{B}, \mathrm{irr}}=\left(\frac{t / 2}{y_{\text {core, } \max }}\right)\left(\varepsilon_{\mathrm{f}}-\varepsilon_{\mathrm{r}}\right) .
$$

As the $\varepsilon_{\mathrm{f}}-\varepsilon_{\mathrm{r}}$ value at $y_{\text {core }}=y_{\text {core,max }}$ is different from specimen to specimen, the $\varepsilon_{\mathrm{B}, \text { irr }}[\mathrm{Eq}$. (3)] is also different from specimen to specimen.

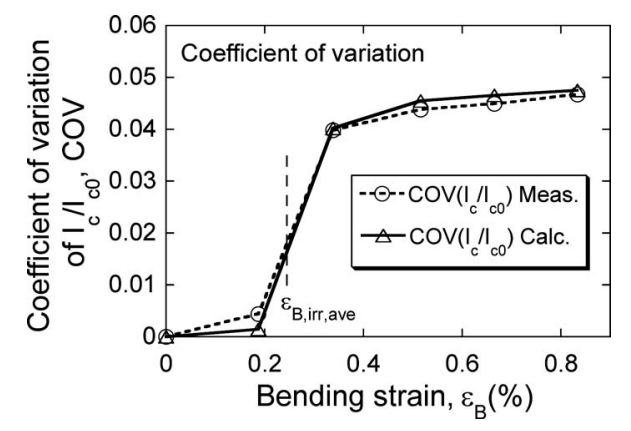

FIG. 3. Change in the measured $\mathrm{COV}$ of $(\square) I_{\mathrm{c}}$ and $(\bigcirc) I_{\mathrm{c}} / I_{\mathrm{c} 0}$ values with bending strain $\varepsilon_{\mathrm{B}}$. $\triangle$ shows the $\mathrm{COV}$ of $I_{\mathrm{c}} / I_{\mathrm{c} 0}$ values calculated with model S-based equation (5) using the estimated distribution function of $\varepsilon_{\mathrm{f}}-\varepsilon_{\mathrm{r}}$ values at each bending strain.
The $I_{\mathrm{c}} / I_{\mathrm{c} 0}$ is 1 (unity) for $\varepsilon_{\mathrm{B}} \leq \varepsilon_{\mathrm{B}, \text { irr }}$. For $\varepsilon_{\mathrm{B}}>\varepsilon_{\mathrm{B}, \text { irr }}$, the damage front $y_{\mathrm{f}}$ extends downward [Fig. 4(c)]. The damage extension reduces the cross-sectional area of the currenttransporting Bi2223 filaments and therefore also reduces $I_{\mathrm{c}} / I_{\mathrm{c} 0} \cdot I_{\mathrm{c}} / I_{\mathrm{c} 0}$ is given by the ratio of the cross-sectional area of the surviving (undamaged) region $\left(-y_{\text {core, } \max } \leq y \leq y_{\mathrm{f}}\right)$ to that of the overall core $A_{\text {core }}$.

$$
\frac{I_{\mathrm{c}}}{I_{\mathrm{c} 0}}=1-2 \int_{0}^{W_{\text {core }} / 2}\left(y_{\text {core }}-y_{\mathrm{f}}\right) d x / A_{\text {core }} \text {. }
$$

Substituting $y_{\text {core }}$ [Eq. (1)] and $y_{\mathrm{f}}$ [Eq. (2)] into Eq. (4), we obtain
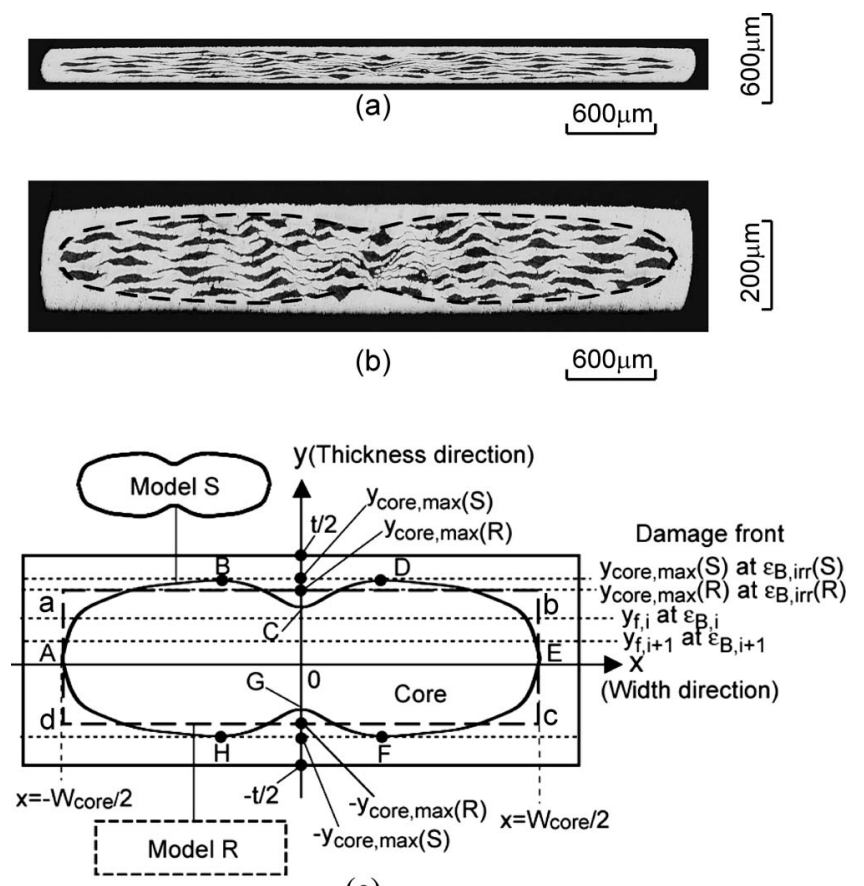

(c)

FIG. 4. Transverse cross section of composite tape. (a) Observed optical micrograph. (b) Modified micrograph, in which thickness direction is enlarged three times compared with (a). The broken curve in (b) shows the shape of the core. (c) Schematic representation of geometry of cross section and core boundary for models $\mathrm{S}$ and $\mathrm{R}$, together with definition of $x$ and $y$. Under applied bending strain, damage to Bi2223 filaments in core occurs first at $y_{\text {core,max }}$ when bending strain reaches $\varepsilon_{\mathrm{B}, \text { irr }}$. For bending strain beyond $\varepsilon_{\mathrm{B}, \text { irr }}$, damage front $\mathrm{y}_{\mathrm{f}}$ moves from $\mathrm{y}_{\text {coremax }}$ to $y_{\mathrm{f}, \mathrm{i}}$ and then $y_{\mathrm{f}, \mathrm{i}+1}$ with increasing bending strain from $\varepsilon_{\mathrm{B}, \text { irr }}$ to $\varepsilon_{\mathrm{B}, \mathrm{i}}$ and then $\varepsilon_{\mathrm{B}, \mathrm{i}+1}$. 


$$
\begin{aligned}
& \frac{I_{\mathrm{c}}}{I_{\mathrm{c} 0}}=1 \quad \text { for } \quad \varepsilon_{\mathrm{B}} \leq \varepsilon_{\mathrm{B}, \mathrm{irr}} \\
& \left.\frac{I_{\mathrm{c}}}{I_{\mathrm{c} 0}}=1-2 \int_{0}^{W_{\text {core }} / 2}\left\{y_{\text {core }}-\frac{\left(\varepsilon_{\mathrm{f}}-\varepsilon_{\mathrm{r}}\right)(t / 2)}{\varepsilon_{\mathrm{B}}}\right\} \frac{d x}{A_{\text {core }}} \quad \text { for } \quad \varepsilon_{\mathrm{B}} \geq \varepsilon_{\mathrm{B}, \mathrm{irr}}\right\} .
\end{aligned}
$$

\section{B. Model R}

The shape of the core was approximated as a rectangle, denoted as abcd in Fig. 4(c). The $x$ - and $y$-positions of the boundary of the core, $x_{\text {core }}$ and $y_{\text {core }}$, respectively, were expressed by Eq. (6) below. The length unit is millimeters.

$$
\begin{aligned}
& \text { ab: } y_{\text {core }}=0.0846 \text { for }-1.95 \leq x \leq 1.95, \quad \text { bc: } x_{\text {core }} \\
& =1.95 \text { for }-0.846 \leq y \leq 0.0846 \text {, } \\
& \text { cd: } y_{\text {core }}=-0.0846 \text { for }-1.95 \leq x \\
& \leq 1.95, \text { da: } x_{\text {core }}=-1.95 \text { for }-0.0846 \\
& \leq y \leq 0.0846 \text {. }
\end{aligned}
$$

In model R, Eqs. (2)-(5) are also retained. Due to the simplification of the shape of the core in model $\mathrm{R}, I_{\mathrm{c}} / I_{\mathrm{c} 0}(<1)$ expressed by Eq. (4) is reduced to

$$
\frac{I_{\mathrm{c}}}{I_{\mathrm{c} 0}}=\frac{1}{2}\left[1+\frac{y_{\mathrm{f}} /(t / 2)}{y_{\mathrm{core}, \max }(\mathrm{R}) /(t / 2)}\right]
$$

The terms $y_{\mathrm{f}} /(t / 2)$ and $y_{\text {core, } \max }(\mathrm{R}) /(t / 2)$ are the relative locations of the damage front and the outermost point of the core in the thickness direction in model R, respectively. In Eq. (2), $y_{\mathrm{f}} /(t / 2)$ is dependent on $\varepsilon_{\mathrm{f}}-\varepsilon_{\mathrm{r}}$ and $\varepsilon_{\mathrm{B}}$. Combining Eq. (2) with Eq. (7), we obtain

$$
\left.\begin{array}{l}
\frac{I_{\mathrm{c}}}{I_{\mathrm{c} 0}}=1 \quad \text { for } \quad \varepsilon_{\mathrm{B}} \leq \varepsilon_{\mathrm{B}, \text { irr }} \\
\frac{I_{\mathrm{c}}}{I_{\mathrm{c} 0}}=\frac{1}{2}\left[1+\left(\frac{t / 2}{y_{\text {core, } \max }(\mathrm{R})}\right)\left(\frac{\varepsilon_{\mathrm{f}}-\varepsilon_{\mathrm{r}}}{\varepsilon_{\mathrm{B}}}\right)\right] \text { for } \varepsilon_{\mathrm{B}} \geq \varepsilon_{\mathrm{B}, \text { irr }}
\end{array}\right\} .
$$

When the distribution function of $\varepsilon_{\mathrm{f}}-\varepsilon_{\mathrm{r}}$ values is known in advance, the distribution of $I_{\mathrm{c}} / I_{\mathrm{c} 0}$ can be calculated with Eqs. (5) and (8) in models $\mathrm{S}$ and $\mathrm{R}$, respectively.

\section{FORMULATION OF DISTRIBUTION FUNCTION OF $I_{\mathrm{c}} / I_{\mathrm{c} 0}$ VALUES AT $\varepsilon_{\mathrm{B}}=0.338 \%, 0.516 \%, 0.665 \%$, AND $0.833 \%$ WHERE ALL SPECIMENS ARE DAMAGED}

\section{A. Estimation of distribution of $\varepsilon_{\mathrm{f}}-\varepsilon_{\mathrm{r}}$ values using model $S$}

If the distribution function of $\varepsilon_{\mathrm{f}}-\varepsilon_{\mathrm{r}}$ and the geometrical factors $\left(y_{\text {core }}, t, A_{\text {core }}\right.$, and $\left.W_{\text {core }}\right)$ are known in advance, the distribution of $I_{\mathrm{c}} / I_{\mathrm{c} 0}$ can be calculated with Eq. (5). However, the distribution of $\varepsilon_{\mathrm{f}}-\varepsilon_{\mathrm{r}}$ values is unknown in practice, while the geometrical factors were estimated as shown in Sec. IV. In this subsection, the $\varepsilon_{\mathrm{f}}-\varepsilon_{\mathrm{r}}$ values were estimated by substituting the measured $I_{\mathrm{c}} / I_{\mathrm{c} 0}$ values (Fig. 1) and geometrical factors into Eq. (5). Then, the distribution function of $\varepsilon_{\mathrm{f}}-\varepsilon_{\mathrm{r}}$ values was formulated as follows.

Unless all tested specimens are damaged, the distribution of $\varepsilon_{\mathrm{f}}-\varepsilon_{\mathrm{r}}$ values cannot be obtained. In the present work, all specimens were damaged at bending strains of $\varepsilon_{\mathrm{B}}=0.338 \%$, $0.516 \%, 0.665 \%$, and $0.833 \%$ (Fig. 1). Substituting the measured $I_{\mathrm{c}} / I_{\mathrm{c} 0}$ values at these bending strains, the $y_{\text {core }}$ expressed by Eq. (1), and the measured values of the geometrical parameters $\left(y_{\text {core, } \max }=0.101 \mathrm{~mm}, W_{\text {core }}=3.90 \mathrm{~mm}, t\right.$ $=0.230 \mathrm{~mm}$, and $A_{\text {core }}=0.660 \mathrm{~mm}^{2}$ ) into Eq. (5), the $\varepsilon_{\mathrm{f}}-\varepsilon_{\mathrm{r}}$ values were estimated. The cumulative probability $F\left(\varepsilon_{\mathrm{f}}-\varepsilon_{\mathrm{r}}\right)$ for the estimated $\varepsilon_{\mathrm{f}}-\varepsilon_{\mathrm{r}}$ values at each bending strain is shown in Figs. 5(a)-5(d).

To describe the strength distribution of materials, the three-parameter Weibull distribution function has been widely employed. ${ }^{25}$ The $\varepsilon_{\mathrm{f}}-\varepsilon_{\mathrm{r}}$ values estimated in the present work were also formulated using this distribution function as follows. According to this function, the cumulative probability $F$ is expressed by

$$
F\left(\varepsilon_{\mathrm{f}}-\varepsilon_{\mathrm{r}}\right)=1-\exp \left\{-\left(\frac{\varepsilon_{\mathrm{f}}-\varepsilon_{\mathrm{r}}-\left(\varepsilon_{\mathrm{f}}-\varepsilon_{\mathrm{r}}\right)_{\min }}{\left(\varepsilon_{\mathrm{f}}-\varepsilon_{\mathrm{r}}\right)_{0}}\right)^{m}\right\} .
$$

Here, $\left(\varepsilon_{\mathrm{f}}-\varepsilon_{\mathrm{r}}\right)_{\min },\left(\varepsilon_{\mathrm{f}}-\varepsilon_{\mathrm{r}}\right)_{0}$, and $m$ are the minimum value of $\varepsilon_{\mathrm{f}}-\varepsilon_{\mathrm{r}}$ below which no values exist, the scale parameter, and the shape parameter, respectively. The Weibull parameters $\left[\left(\varepsilon_{\mathrm{f}}-\varepsilon_{\mathrm{r}}\right)_{\min }, m\right.$, and $\left.\left(\varepsilon_{\mathrm{f}}-\varepsilon_{\mathrm{r}}\right)_{0}\right]$ for the distribution of $\varepsilon_{\mathrm{f}}-\varepsilon_{\mathrm{r}}$ values were estimated by regression analysis. Equation (9) is rewritten in the form $\ln \ln (1-F)^{-1}=m \ln \left\{\varepsilon_{\mathrm{f}}-\varepsilon_{\mathrm{r}}-\left(\varepsilon_{\mathrm{f}}\right.\right.$ $\left.\left.-\varepsilon_{\mathrm{r}}\right)_{\min }\right\}-m \ln \left\{\left(\varepsilon_{\mathrm{f}}-\varepsilon_{\mathrm{r}}\right)_{0}\right\}$. Figures $5\left(\mathrm{a}^{\prime}\right)-5\left(\mathrm{~d}^{\prime}\right)$ show the plot of $\ln \ln (1-F)^{-1}$ against $\ln \left\{\varepsilon_{\mathrm{f}}-\varepsilon_{\mathrm{r}}-\left(\varepsilon_{\mathrm{f}}-\varepsilon_{\mathrm{r}}\right)_{\text {min }}\right\}$ with the bestfit values of $\left(\varepsilon_{\mathrm{f}}-\varepsilon_{\mathrm{r}}\right)_{\min }$. The linear correlation between $\ln \ln (1-F)^{-1}$ and $\ln \left\{\varepsilon_{\mathrm{f}}-\varepsilon_{\mathrm{r}}-\left(\varepsilon_{\mathrm{f}}-\varepsilon_{\mathrm{r}}\right)_{\min }\right\}$ is high, indicating the $\varepsilon_{\mathrm{f}}-\varepsilon_{\mathrm{r}}$ values are well described by this function. The parameters $\left[\left(\varepsilon_{\mathrm{f}}-\varepsilon_{\mathrm{r}}\right)_{\min }, m\right.$, and $\left.\left(\varepsilon_{\mathrm{f}}-\varepsilon_{\mathrm{r}}\right)_{0}\right]$ were estimated to be $(0.130 \%, 4.19,0.0928 \%),(0.125 \%, 4.23,0.124 \%)$, $(0.122 \%, 3.74,0.128 \%)$, and $(0.079 \%, 3.60,0.144 \%)$ at $\varepsilon_{\mathrm{B}}$ $=0.338 \%, 0.516 \%, 0.665 \%$, and $0.833 \%$, respectively. The average of $\varepsilon_{\mathrm{f}}-\varepsilon_{\mathrm{r}}$ values at $\varepsilon_{\mathrm{B}}=0.338 \%-0.833 \%,\left(\varepsilon_{\mathrm{f}}-\varepsilon_{\mathrm{r}}\right)_{\mathrm{av}}$, is $0.214 \%$, which is in good agreement with the value of $0.22 \%$ estimated in our preceding work for the present sample. ${ }^{11}$

\section{B. Formulation of distribution of $I_{\mathrm{c}} / I_{\mathrm{c} 0}$ values at $\varepsilon_{\mathrm{B}}$ $=0.338 \%, 0.516 \%, 0.665 \%$, and $0.833 \%$ using estimated distribution function of $\varepsilon_{\mathrm{f}}-\varepsilon_{\mathrm{r}}$ values}

By combining the distribution function of $\varepsilon_{\mathrm{f}}-\varepsilon_{\mathrm{r}}$ values expressed by Eq. (9) with Eq. (5), and substituting $y_{\text {core }}$ [Eq. (1)], the known values of $t / 2, A_{\text {core }}$, and $\varepsilon_{\mathrm{B}}$, and the esti- 

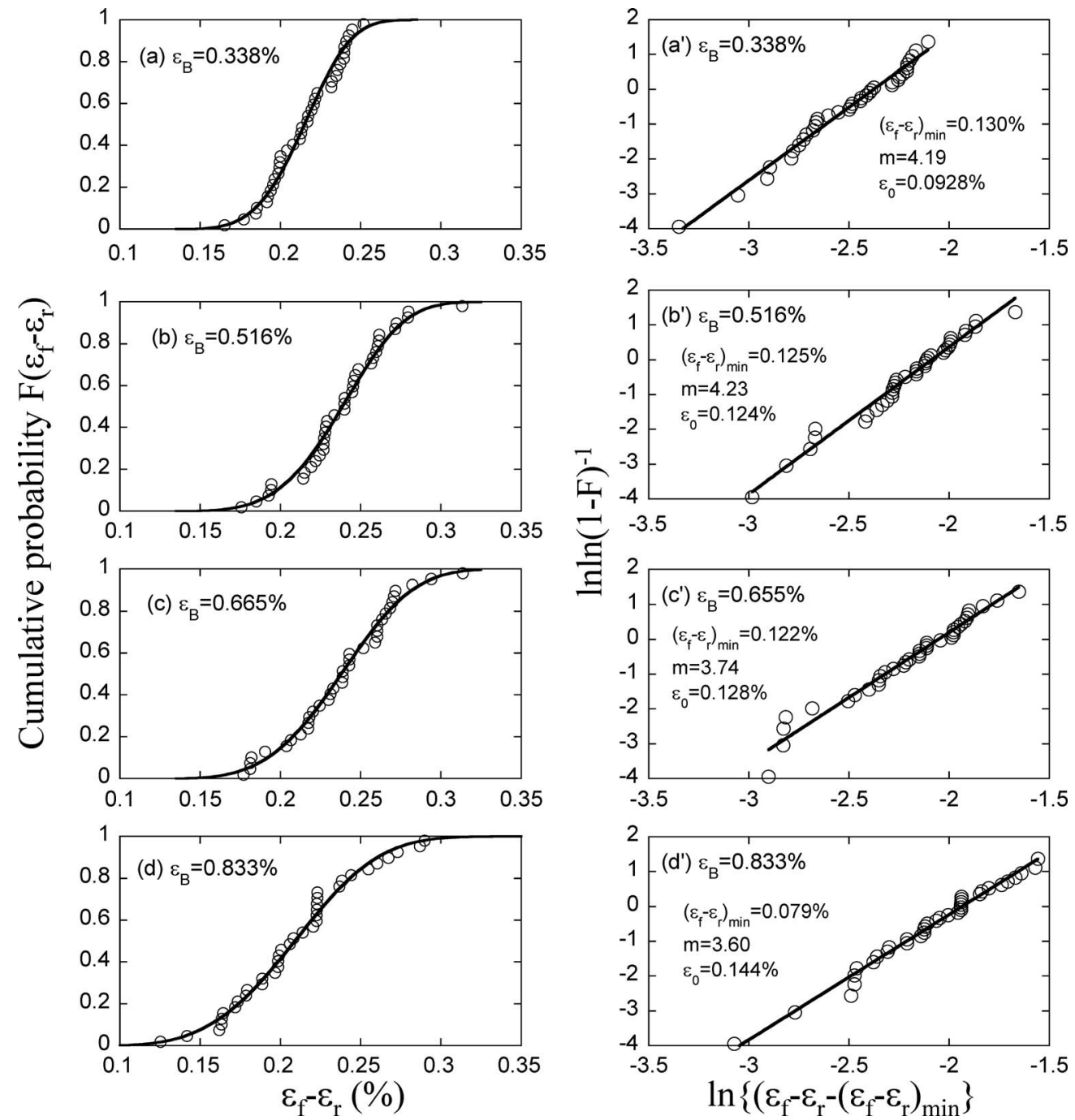

FIG. 5. Cumulative probability of $\varepsilon_{\mathrm{f}}-\varepsilon_{\mathrm{r}}$ values and plot of $\ln \ln (1-F)^{-1}$ against $\ln \left\{\varepsilon_{\mathrm{f}}-\varepsilon_{\mathrm{r}}-\left(\varepsilon_{\mathrm{f}}-\varepsilon_{\mathrm{r}}\right)_{\min }\right\}$ with best-fit parameter values at $\varepsilon_{\mathrm{B}}=[(\mathrm{a})$ and (a')] $0.338 \%$, $\left[(\mathrm{b})\right.$ and $\left.\left(\mathrm{b}^{\prime}\right)\right] 0.516 \%,\left[(\mathrm{c})\right.$ and $\left.\left(\mathrm{c}^{\prime}\right)\right] 0.665 \%$, and $\left[(\mathrm{d})\right.$ and $\left.\left(\mathrm{d}^{\prime}\right)\right] 0.833 \%$. The solid curves show the result of regression analysis.

mated values of $\left(\varepsilon_{\mathrm{f}}-\varepsilon_{\mathrm{r}}\right)_{\min }, m$, and $\left(\varepsilon_{\mathrm{f}}-\varepsilon_{\mathrm{r}}\right)_{0}$, we calculated numerically the cumulative $(F)$ and density $(f)$ distributions of $I_{\mathrm{c}} / I_{\mathrm{c} 0}$ at $\varepsilon_{\mathrm{B}}=0.338 \%, 0.516 \%, 0.665 \%$, and $0.833 \%$. The calculation results are presented as solid curves in Figs. 1 and 2. The $\operatorname{COV}\left(I_{\mathrm{c}} / I_{\mathrm{c} 0}\right)$ at each $\varepsilon_{\mathrm{B}}$ was also calculated as shown in Fig. 3. The experimental results were well described. This result indicates that Eq. (9) is useful for describing the distribution of $I_{\mathrm{c}} / I_{\mathrm{c} 0}$ values.

The calculation results (solid curves in Figs. 1 and 2) were obtained numerically. Next, the distribution of the $I_{\mathrm{c}} / I_{\mathrm{c} 0}$ values was formulated as follows. It has been shown that the distribution of the critical current values is empirically described by the three-parameter Weibull distribution when the bending strain is lower than around $1 \%$ where only the tensile side is damaged. ${ }^{13,16}$ Moreover, this function has been shown to be useful for the description of the critical current distribution at weak links. ${ }^{26-29}$

If the three-parameter Weibull distribution function is applicable to describe the distribution of $I_{\mathrm{c}} / I_{\mathrm{c} 0}$ values, the distribution is characterized by three parameters $\left[\left(I_{\mathrm{c}} / I_{\mathrm{c} 0}\right)_{\min }\right.$ : the minimum (lower limit) critical current below which there is no critical current value, $\left(I_{\mathrm{c}} / I_{\mathrm{c} 0}\right)_{0}$ : the scale parameter, and $m$ : the shape parameter). With these parameters, the cumulative probability $F$ of the critical current $\left(I_{\mathrm{c}} / I_{\mathrm{c} 0}\right)$ is expressed by

$$
F\left(I_{\mathrm{c}} / I_{\mathrm{c} 0}\right)=1-\exp \left[1-\left\{\frac{I_{\mathrm{c}} / I_{\mathrm{c} 0}-\left(I_{\mathrm{c}} / I_{\mathrm{c} 0}\right)_{\min }}{\left(I_{\mathrm{c}} / I_{\mathrm{c} 0}\right)_{0}}\right\}^{m}\right] .
$$

When $\left(I_{\mathrm{c}} / I_{\mathrm{c} 0}\right)_{\min }=0$ in Eq. (10), the number of parameters to be estimated by the regression analysis is reduced to two $\left[\left(I_{\mathrm{c}} / I_{\mathrm{c} 0}\right)_{0}\right.$ and $\left.m\right]$. Such a function has been referred to as a two-parameter Weibull function. In the case of the twoparameter Weibull function, the relation of $\ln \ln (1-F)^{-1}$ to $\ln \left(I_{\mathrm{c}} / I_{\mathrm{c} 0}\right)$ is linear. If the $\left(I_{\mathrm{c}} / I_{\mathrm{c} 0}\right)$ values obey the threeparameter function [Eq. (10) with $\left(I_{\mathrm{c}} / I_{\mathrm{c} 0}\right)_{\min }>0$ ], it has been shown that the $\ln \ln (1-F)^{-1}-\ln \left(I_{\mathrm{c}} / I_{\mathrm{c} 0}\right)$ relation is convex. ${ }^{13,16}$ In fact, the $\ln \ln (1-F)^{-1}-\ln \left(I_{\mathrm{c}} / I_{\mathrm{c} 0}\right)$ relations at $\varepsilon_{\mathrm{B}}=0.338 \%, 0.516 \%, 0.665 \%$, and $0.833 \%$, obtained from the calculated $F-I_{\mathrm{c}} / I_{\mathrm{c} 0}$ relations shown as solid curves in Fig. 1, are convex as shown in Fig. 6(a). This suggests mathematically that the $\ln \ln (1-F)^{-1}-\ln \left\{I_{\mathrm{c}} / I_{\mathrm{c} 0}-\left(I_{\mathrm{c}} / I_{\mathrm{c} 0}\right)_{\min }\right\}$ relation is convex for small $\left(I_{\mathrm{c}} / I_{\mathrm{c} 0}\right)_{\min }$ value but is downwardly concave for large $\left(I_{\mathrm{c}} / I_{\mathrm{c} 0}\right)_{\min }$ values, and when $\left(I_{\mathrm{c}} / I_{\mathrm{c} 0}\right)_{\min }$ in- 

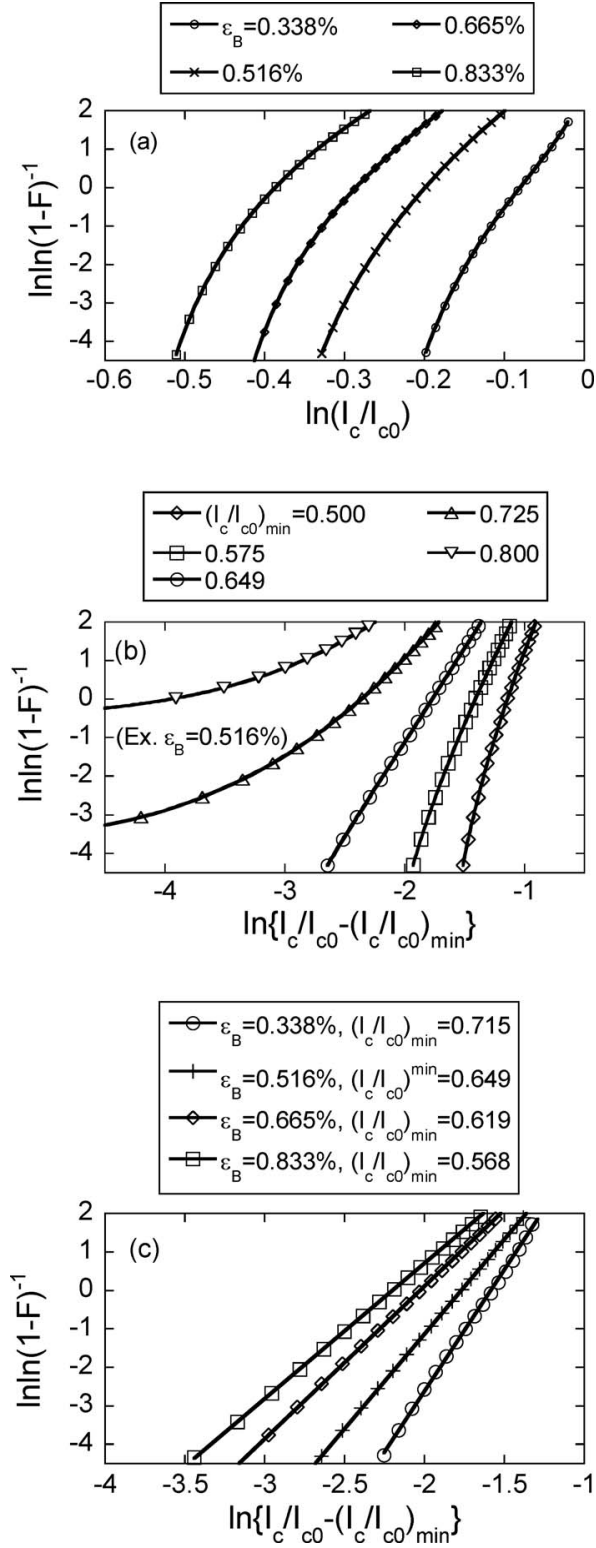

FIG. 6. (a) Plot of $\ln \ln (1-F)^{-1}$ against $\ln \left(I_{\mathrm{c}} / I_{\mathrm{c} 0}\right)$ for $I_{\mathrm{c}} / I_{\mathrm{c} 0}$ values calculated from estimated distribution of $\varepsilon_{\mathrm{f}}-\varepsilon_{\mathrm{r}}$ values at $\varepsilon_{\mathrm{B}}=0.338 \%, 0.516 \%$, $0.665 \%, 0.833 \%$, when convex. (b) Example of change in $\ln \ln (1-F)^{-1}$ $-\ln \left\{I_{\mathrm{c}} / I_{\mathrm{c} 0}-\left(I_{\mathrm{c}} / I_{\mathrm{c} 0}\right)_{\min }\right\}$ curve for varying $\left(I_{\mathrm{c}} / I_{\mathrm{c} 0}\right)_{\min }$ value $\left(\varepsilon_{\mathrm{B}}=0.516 \%\right)$, showing high linearity between $\ln \ln (1-F)^{-1}$ and $\ln \left\{I_{\mathrm{c}} / I_{\mathrm{c} 0}-\left(I_{\mathrm{c}} / I_{\mathrm{c} 0}\right)_{\min }\right\}$ for $\left(I_{\mathrm{c}} / I_{\mathrm{c} 0}\right)_{\min }=0.649$. (c) Linear relation between $\ln \ln (1-F)^{-1}$ and $\ln \left\{I_{\mathrm{c}} / I_{\mathrm{c} 0}\right.$ $\left.-\left(I_{\mathrm{c}} / I_{\mathrm{c} 0}\right)_{\min }\right\}$ for $\left(I_{\mathrm{c}} / I_{\mathrm{c} 0}\right)_{\min }=0.715,0.649,0.619$ and 0.568 at $\varepsilon_{\mathrm{B}}=0.338 \%$, $0.516 \%, 0.665 \%$, and $0.833 \%$, respectively.

creases, the relation of $\ln \ln (1-F)^{-1}$ to $\ln \left\{I_{\mathrm{c}} / I_{\mathrm{c} 0}\right.$ $\left.-\left(I_{\mathrm{c}} / I_{\mathrm{c} 0}\right)_{\min }\right\}$ becomes linear. Taking the case of $\varepsilon_{\mathrm{B}}$ $=0.516 \%$ as a representative example, the plot of $\ln \ln (1$ $-F)^{-1}$ against $\ln \left\{I_{\mathrm{c}} / I_{\mathrm{c} 0}-\left(I_{\mathrm{c}} / I_{\mathrm{c} 0}\right)_{\min }\right\}$ with different $\left(I_{\mathrm{c}} / I_{\mathrm{c} 0}\right)_{\min }$ values is convex when the $\left(I_{\mathrm{c}} / I_{\mathrm{c} 0}\right)_{\min }$ value is low $(0.500$, $0.575)$ but then becomes concave when it is high $(0.725$, 0.800), as shown in Fig. 6(b). From low values of $\left(I_{\mathrm{c}} / I_{\mathrm{c} 0}\right)_{\min }$ to high values, the relation between $\ln \ln (1-F)^{-1}$ and $\ln \left\{I_{\mathrm{c}} / I_{\mathrm{c} 0}-\left(I_{\mathrm{c}} / I_{\mathrm{c} 0}\right)_{\min }\right\}$ is linear, as shown in the case of $\left(I_{\mathrm{c}} / I_{\mathrm{c} 0}\right)_{\min }=0.649$ in this example. In the same way, a linear relation between $\ln \ln (1-F)^{-1}$ and $\ln \left\{I_{\mathrm{c}} / I_{\mathrm{c} 0}-\left(I_{\mathrm{c}} / I_{\mathrm{c} 0}\right)_{\min }\right\}$ is found for $\left(I_{\mathrm{c}} / I_{\mathrm{c} 0}\right)_{\min }=0.715,0.619$, and 0.568 at $\varepsilon_{\mathrm{B}}$ $=0.338 \%, 0.665 \%$, and $0.833 \%$, respectively, as shown in Fig. 6(c).
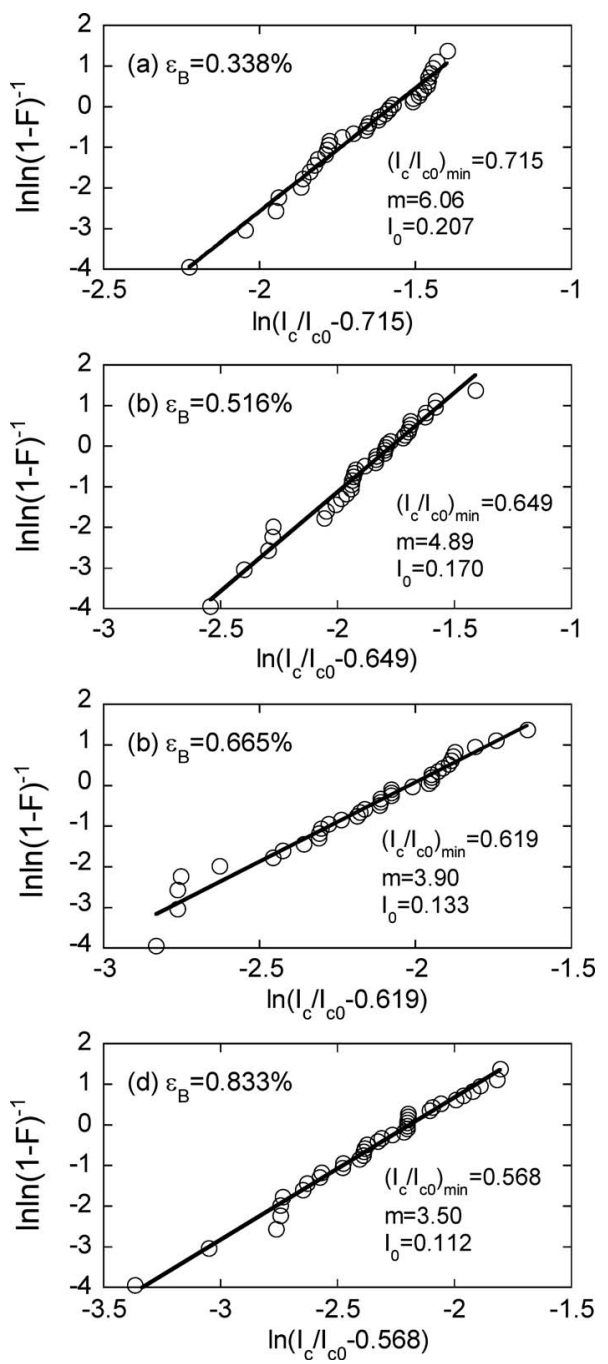

FIG. 7. Plot of $\ln \ln (1-F)^{-1}$ against $\ln \left\{I_{\mathrm{c}} / I_{\mathrm{c} 0}-\left(I_{\mathrm{c}} / I_{\mathrm{c} 0}\right)_{\min }\right\}$ for measured $I_{\mathrm{c}} / I_{\mathrm{c} 0}$ values at $\varepsilon_{\mathrm{B}}=$ (a) $0.338 \%$, (b) $0.516 \%$, (c) $0.665 \%$, and (d) $0.833 \%$. $\left(I_{\mathrm{c}} / I_{\mathrm{c} 0}\right)_{\min }$ values used here were taken from Fig. 6(c).

Figure 7 shows the plot of $\ln \ln (1-F)^{-1}$ against $\ln \left\{I_{\mathrm{c}} / I_{\mathrm{c} 0}-\left(I_{\mathrm{c}} / I_{\mathrm{c} 0}\right)_{\min }\right\}$ for the measured $I_{\mathrm{c}} / I_{\mathrm{c} 0}$ values, in which the $\left(I_{\mathrm{c}} / I_{\mathrm{c} 0}\right)_{\min }$ values estimated in Fig. 6(c) are used. The high linearity between $\ln \ln (1-F)^{-1}$ and $\ln \left\{I_{\mathrm{c}} / I_{\mathrm{c} 0}\right.$ $\left.-\left(I_{\mathrm{c}} / I_{\mathrm{c} 0}\right)_{\min }\right\}$ means that the measured $I_{\mathrm{c}} / I_{\mathrm{c} 0}$ values are well described by the three-parameter Weibull distribution function. From the slope and extrapolation, the values of $m$ and $\left(I_{\mathrm{c}} / I_{\mathrm{c} 0}\right)_{0}$ were estimated. The estimated values of $\left\{\left(I_{\mathrm{c}} / I_{\mathrm{c} 0}\right)_{\min }\right.$, $\left.m,\left(I_{\mathrm{c}} / I_{\mathrm{c} 0}\right)_{0}\right\}$ were $(0.715,6.06,0.207),(0.649,4.89,0.170)$, $(0.619,3.90,0.133)$, and $(0.568,3.50,0.112)$ at $\varepsilon_{\mathrm{B}}$ $=0.338 \%, 0.516 \%, 0.665 \%$, and $0.833 \%$, respectively.

Substituting the estimated parameter values of $\left(I_{\mathrm{c}} / I_{\mathrm{c} 0}\right)_{\min }, m$, and $\left(I_{\mathrm{c}} / I_{\mathrm{c} 0}\right)_{0}$ into Eq. $(10)$, the relations between cumulative probability $F$ and critical current $I_{\mathrm{c}} / I_{\mathrm{c} 0}$ at $\varepsilon_{\mathrm{B}}=0.338 \%, 0.516 \%, 0.665 \%$, and $0.833 \%$ were calculated, which were the same as those shown as solid curves in Fig. 1. Furthermore, with the estimated parameter values, the cumulative probability $F$ [Eq. (10)] was converted to the density probability $f$ (frequency). The obtained relations between $f$ and $I_{\mathrm{c}} / I_{\mathrm{c} 0}$ were the same as those shown as solid curves in Fig. 2. These results demonstrate that the approach using model $\mathrm{S}$ is a useful tool for reproduction of the experi- 
mental results, and that the distribution of $I_{\mathrm{c}} / I_{\mathrm{c} 0}$ values is described well by the three-parameter Weibull distribution function. However, at this stage, the approach is empirical since the parameter values of $\left(I_{\mathrm{c}} / I_{\mathrm{c} 0}\right)_{\min }, m$, and $\left(I_{\mathrm{c}} / I_{\mathrm{c} 0}\right)_{0}$ were estimated as fitting parameters and their physical significance is unknown. In Sec. V C, it is shown that the critical current distribution can be formulated in the form of the three-parameter Weibull distribution function directly by application of model $\mathrm{R}$, and the physical meaning of the parameter values estimated in the present subsection is clarified.

\section{Direct derivation of three-parameter Weibull distribution function using model $\mathbf{R}$}

The terms $y_{\mathrm{f}} /(t / 2)$ in Eq. (2) and $y_{\text {core, } \max } /(t / 2)$ in Eq. (3) are the relative locations of the damage front and outermost point of the core in the thickness direction, respectively. As $y_{\text {core,max }}(\mathrm{S}) /(t / 2)$ (model $\mathrm{S}$ ) and $y_{\text {core, } \max }(\mathrm{R}) /(t / 2)$ (model $\mathrm{R})$ were 0.878 and 0.736 , respectively, and $t=0.23 \mathrm{~mm}$, the $I_{\mathrm{c}} / I_{\mathrm{c} 0}$ can be calculated as a function of relative damage front location, $y_{\mathrm{f}} /(t / 2)$, with Eqs. (4) and (7) for models $\mathrm{S}$ and R, respectively. The result is shown in Fig. 8(a). The damage initiates at $y_{\text {core, } \max }(\mathrm{R}) /(t / 2)$ and $y_{\text {core, max }}(\mathrm{S}) /(t / 2)$ in models $\mathrm{R}$ and $\mathrm{S}$, respectively. The difference in the $I_{\mathrm{c}} / I_{\mathrm{c} 0}-\varepsilon_{\mathrm{B}}$ relation between models $\mathrm{S}$ and $\mathrm{R}$ is large in the range of $I_{\mathrm{c}} / I_{\mathrm{c} 0}$ $>0.8$. However, for the range of $I_{\mathrm{c}} / I_{\mathrm{c} 0}<0.8$, both models give nearly identical results. Thus, the measured $I_{\mathrm{c}} / I_{\mathrm{c} 0}-\varepsilon_{\mathrm{B}}$ relation in a relatively high bending strain range can be described in a similar manner by both models. Taking the case of the variation of average of $I_{\mathrm{c}} / I_{\mathrm{c} 0}$ values, $\left(I_{\mathrm{c}} / I_{\mathrm{c} 0}\right)_{\mathrm{av}}$, with bending strain $\varepsilon_{\mathrm{B}}$, the values of $\left(I_{\mathrm{c}} / I_{\mathrm{c} 0}\right)_{\mathrm{av}}$ calculated using model S [Eq. (5)] and model R [Eq. (8)] for the average of $\varepsilon_{\mathrm{f}}-\varepsilon_{\mathrm{r}}$ values, $\left(\varepsilon_{\mathrm{f}}-\varepsilon_{\mathrm{r}}\right)_{\mathrm{av}}=0.214 \%$, are almost the same at high bending strains, as shown in Fig. 8(b). As Eq. (8) is a good
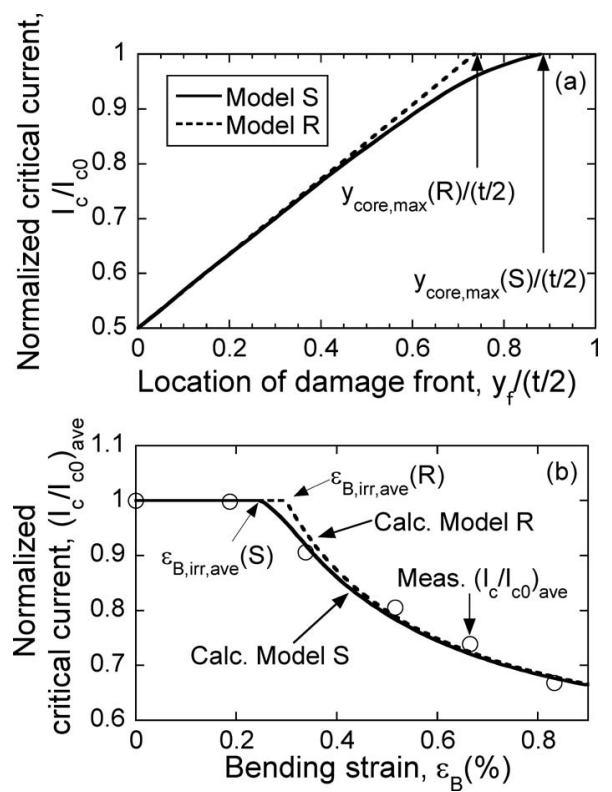

FIG. 8. Comparison of relation of $I_{\mathrm{c}} / I_{\mathrm{c} 0}$ to damage front $y_{\mathrm{f}} /(t / 2)$ and variation of average critical current $\left(I_{\mathrm{c}} / I_{\mathrm{c} 0}\right)_{\mathrm{av}}$ with bending strain $\varepsilon_{\mathrm{B}}$ between models $\mathrm{S}$ and R. (a) Relation of $I_{\mathrm{c}} / I_{\mathrm{c} 0}$ to $y_{\mathrm{f}} /(t / 2)$, as calculated using models $\mathrm{R}$ and S. (b) Measured and analyzed variation of $\left(I_{\mathrm{c}} / I_{\mathrm{c} 0}\right)_{\mathrm{av}}$ with $\varepsilon_{\mathrm{B}}$. The results analyzed by models $\mathrm{S}$ and $\mathrm{R}$ with $\left(\varepsilon_{\mathrm{f}}-\varepsilon_{\mathrm{r}}\right)_{\mathrm{av}}=0.214 \%$ are shown as solid and broken curves, respectively. Average irreversible bending strains $\varepsilon_{\mathrm{B}, \text { irrav }}$ analyzed by models $\mathrm{S}(0.243 \%)$ and $\mathrm{R}(0.291 \%)$ are indicated with arrows.

approximation of Eq. (5) at high $\varepsilon_{\mathrm{B}}$, Eq. (8) is used below for direct formulation of the distribution of $I_{\mathrm{c}} / I_{\mathrm{c} 0}$ values at $\varepsilon_{\mathrm{B}}$ $=0.665 \%$ and $0.833 \%$.

$I_{\mathrm{c}} / I_{\mathrm{c} 0}$ for $\varepsilon_{\mathrm{B}} \geq \varepsilon_{\mathrm{B}, \text { irr }}$ expressed by Eq. (8) contains the term $\varepsilon_{\mathrm{f}}-\varepsilon_{\mathrm{r}}$, which is distributed according to Eq. (9). Substituting $\varepsilon_{\mathrm{f}}-\varepsilon_{\mathrm{r}}=\left\{2\left(I_{\mathrm{c}} / I_{\mathrm{c} 0}\right)-1\right\} \varepsilon_{\mathrm{B}}\left\{y_{\text {core, } \max }(\mathrm{R}) /(t / 2)\right\}$ derived from Eq. (8) into Eq. (9), we obtain

$$
F\left(I_{\mathrm{c}} / I_{\mathrm{c} 0}\right)=1-\exp \left(-\left[\frac{I_{\mathrm{c}} / I_{\mathrm{c} 0}-\frac{1}{2}\left(1+\frac{\left(\varepsilon_{\mathrm{f}}-\varepsilon_{\mathrm{r}}\right)_{\min }}{\varepsilon_{\mathrm{B}}\left\{y_{\text {core, } \max }(\mathrm{R}) /(t / 2)\right\}}\right)}{\frac{\left(\varepsilon_{\mathrm{f}}-\varepsilon_{\mathrm{r}}\right)_{0}}{2 \varepsilon_{\mathrm{B}}\left\{y_{\text {core, } \max }(\mathrm{R}) /(t / 2)\right\}}}\right]^{m}\right) .
$$

Substituting $\quad\left\{\left(\varepsilon_{\mathrm{f}}-\varepsilon_{\mathrm{r}}\right)_{\min }, m,\left(\varepsilon_{\mathrm{f}}-\varepsilon_{\mathrm{r}}\right)_{0}\right\}=(0.122 \%, 3.74$, $0.128 \%)$ and $(0.079 \%, 3.60,0.144 \%)$ at $\varepsilon_{\mathrm{B}}=0.665 \%$ and $0.833 \%$, respectively, and $y_{\text {core, } \max }(\mathrm{R}) /(t / 2)=0.736$ into Eq. (11), the relation between cumulative probability $F$ and critical current $I_{\mathrm{c}} / I_{\mathrm{c} 0}$ was calculated. The result is shown as broken curves in Fig. 9. The $F-I_{\mathrm{c}} / I_{\mathrm{c} 0}$ relations calculated with Eq. (11) (model R) are very close to those (solid curves) calculated with Eq. (5) (model S). The measured distributions of $I_{\mathrm{c}} / I_{\mathrm{c} 0}$ values at $\varepsilon_{\mathrm{B}}=0.665 \%$ and $0.833 \%$ are well described by both Eqs. (5) and (11). Furthermore, the $f$ $-I_{\mathrm{c}} / I_{\mathrm{c} 0}$ relation was calculated by conversion of the $F$ $-I_{\mathrm{c}} / I_{\mathrm{c} 0}$ relation. The calculation results obtained using model $\mathrm{R}$ are shown as broken curves in Figs. 2(e) and 2(f); the

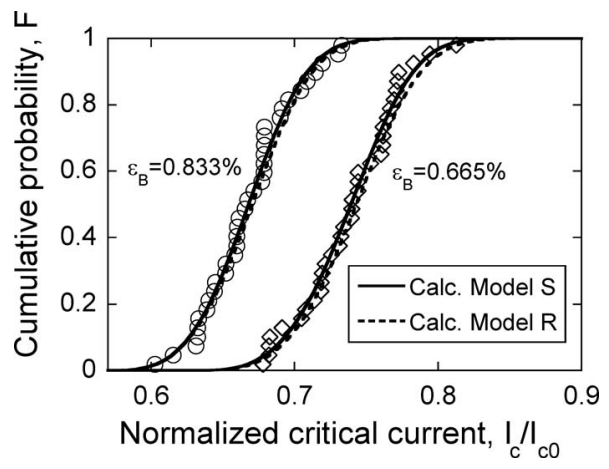

FIG. 9. Comparison of cumulative probability $F\left(I_{\mathrm{c}} / I_{\mathrm{c} 0}\right)$ of critical current $I_{\mathrm{c}} / I_{\mathrm{c} 0}$ calculated using models $\mathrm{S}$ and $\mathrm{R}$ with measured values at $\varepsilon_{\mathrm{B}}$ $=0.665 \%$ and $0.833 \%$ where maximum $I_{\mathrm{c}} / I_{\mathrm{c} 0}$ values were less than 0.8 . 
experimental results are described as well as those (solid curves) calculated using model S.

As shown in Sec. V B, the distribution of $I_{\mathrm{c}} / I_{\mathrm{c} 0}$ values calculated using model $\mathrm{S}$ was described by the threeparameter Weibull distribution [Fig. 6(c)], which described the measured distribution of the $I_{\mathrm{c}} / I_{\mathrm{c} 0}$ values well (Fig. 7). The distribution calculated using model $\mathrm{R}$ was almost the same as that calculated using model S. These results signify that Eq. (11) can be rewritten in the form of Eq. (10) by taking

$$
\begin{aligned}
& \left(I_{\mathrm{c}} / I_{\mathrm{c} 0}\right)_{\min }=\frac{1}{2}\left[1+\frac{\left(\varepsilon_{\mathrm{f}}-\varepsilon_{\mathrm{r}}\right)_{\min }}{\varepsilon_{\mathrm{B}}\left\{y_{\text {core, } \max }(\mathrm{R}) /(t / 2)\right\}}\right], \\
& \left(I_{\mathrm{c}} / I_{\mathrm{c} 0}\right)_{0}=\frac{\left(\varepsilon_{\mathrm{f}}-\varepsilon_{\mathrm{r}}\right)_{0}}{2 \varepsilon_{\mathrm{B}}\left\{y_{\text {core, } \max }(\mathrm{R}) /(t / 2)\right\}}, \\
& m \text { for } I_{\mathrm{c}} / I_{\mathrm{c} 0}=m \text { for } \varepsilon_{\mathrm{f}}-\varepsilon_{\mathrm{r}} .
\end{aligned}
$$

In Eq. $(12), \quad\left(\varepsilon_{\mathrm{f}}-\varepsilon_{\mathrm{r}}\right)_{\min }$ is expressed by $\left(\varepsilon_{\mathrm{f}}-\varepsilon_{\mathrm{r}}\right)_{\min }$ $=\varepsilon_{\mathrm{B}} y_{\mathrm{f}, \min } /(t / 2)$ from Eq. (2) where $y_{\mathrm{f}, \min }$ is the lowest damage front (damage front of the most damaged specimen) among the specimens. Substituting this relation into Eq. (12), we obtain

$$
\left(I_{\mathrm{c}} / I_{\mathrm{c} 0}\right)_{\min }=\frac{1}{2}\left\{1+\frac{y_{\mathrm{f}, \min }}{y_{\text {core, } \max }(\mathrm{R})}\right\} .
$$

The right term in Eq. (15) corresponds to the ratio of the nondamaged cross-sectional area of the core to the overall cross-sectional area in the most damaged specimen. Therefore the physical meaning of $\left(I_{\mathrm{c}} / I_{\mathrm{c} 0}\right)_{\min }$, below which no critical current value exists, is expressed exactly by Eq. (12).

From Eq. (10), the relation of $\left(I_{\mathrm{c}} / I_{\mathrm{c} 0}\right)_{0}$ to the average of the $I_{\mathrm{c}} / I_{\mathrm{c} 0}$ values, $\left(I_{\mathrm{c}} / I_{\mathrm{c} 0}\right)_{\mathrm{av}}$, and the minimum $I_{\mathrm{c}} / I_{\mathrm{c} 0}$ value among the specimens, $\left(I_{\mathrm{c}} / I_{\mathrm{c} 0}\right)_{\min }$, is calculated as

$$
\begin{aligned}
\left(I_{\mathrm{c}} / I_{\mathrm{c} 0}\right)_{\mathrm{av}} & =\int_{\left(I_{\mathrm{c}} / I_{\mathrm{c} 0}\right)_{\min }}^{1}\left[\left(I_{\mathrm{c}} / I_{\mathrm{c} 0}\right) \frac{d F\left(I_{\mathrm{c}} / I_{\mathrm{c} 0}\right)}{d\left(I_{\mathrm{c}} / I_{\mathrm{c} 0}\right)}\right] d\left(I_{\mathrm{c}} / I_{\mathrm{c} 0}\right) \\
& =\left(I_{\mathrm{c}} / I_{\mathrm{c} 0}\right)_{0} \Gamma(1+1 / m)+\left(I_{\mathrm{c}} / I_{\mathrm{c} 0}\right)_{\min },
\end{aligned}
$$

where $\Gamma$ is the gamma function. Thus, the $\left(I_{\mathrm{c}} / I_{\mathrm{c} 0}\right)_{0}$ is expressed as

$$
\left(I_{\mathrm{c}} / I_{\mathrm{c} 0}\right)_{0}=\frac{\left(I_{\mathrm{C}} / I_{\mathrm{c} 0}\right)_{\mathrm{av}}-\left(I_{\mathrm{c}} / I_{\mathrm{c} 0}\right)_{\min }}{\Gamma(1+1 / m)} .
$$

The scale parameter $\left(I_{\mathrm{c}} / I_{\mathrm{c} 0}\right)_{0}$ is a measure of the range of variation of the $I_{\mathrm{c}} / I_{\mathrm{c} 0}$ values. Such a physical meaning of this parameter is expressed exactly by Eq. (13), as shown below.

Using Eq. (9), we obtain the average of the $\varepsilon_{\mathrm{f}}-\varepsilon_{\mathrm{r}}$ values, $\left(\varepsilon_{\mathrm{f}}-\varepsilon_{\mathrm{r}}\right)_{\mathrm{av}}$,

$$
\left(\varepsilon_{\mathrm{f}}-\varepsilon_{\mathrm{r}}\right)_{\mathrm{av}}=\left(\varepsilon_{\mathrm{f}}-\varepsilon_{\mathrm{r}}\right)_{0} \Gamma(1+1 / m)+\left(\varepsilon_{\mathrm{f}}-\varepsilon_{\mathrm{r}}\right)_{\min } .
$$

The relation of the damage front $y_{\mathrm{f}}$ to $\varepsilon_{\mathrm{f}}-\varepsilon_{\mathrm{r}}$ under a given bending strain $\varepsilon_{\mathrm{B}}$ was obtained as Eq. (2). Denoting the average location of the damage front as $y_{\mathrm{f}, \mathrm{av}}$, and substituting $\left(\varepsilon_{\mathrm{f}}-\varepsilon_{\mathrm{r}}\right)_{\mathrm{av}}=y_{\mathrm{f}, \mathrm{av}} \varepsilon_{\mathrm{B}} /(t / 2)$ and $\left(\varepsilon_{\mathrm{f}}-\varepsilon_{\mathrm{r}}\right)_{\min }=y_{\mathrm{f}, \min } \varepsilon_{\mathrm{B}} /(t / 2)$ [Eq. (2)] into Eq. (18) and then Eq. (13), we obtain

$$
\left(I_{\mathrm{c}} / I_{\mathrm{c} 0}\right)_{0}=\frac{y_{\mathrm{f}, \mathrm{av}}-y_{\mathrm{f}, \min }}{2 y_{\text {core, } \max }(\mathrm{R}) \Gamma(1+1 / m)} .
$$

In Eq. (19), $\left(y_{\mathrm{f}, \mathrm{av}}-y_{\mathrm{f}, \mathrm{min}}\right) / 2 y_{\text {core,max }}(\mathrm{R})$ is the ratio of the difference in "average minus minimum" cross-sectional area of the nondamaged part of the core to the overall crosssectional area of the core, which is exactly equal to $\left(I_{\mathrm{c}} / I_{\mathrm{c} 0}\right)_{\mathrm{av}}-\left(I_{\mathrm{c}} / I_{\mathrm{c} 0}\right)_{\min }$ in model R. Thus, $\left(I_{\mathrm{c}} / I_{\mathrm{c} 0}\right)_{0}$ given by Eq. (13) is exactly the same as that given by Eq. (17), having physical meaning as a measure of the distributed range of $I_{\mathrm{c}} / I_{\mathrm{c} 0}$ values.

It is important to note that the value of $m$ for distribution of $I_{\mathrm{c}} / I_{\mathrm{c} 0}$ is the same as that for the distribution of $\varepsilon_{\mathrm{f}}-\varepsilon_{\mathrm{r}}$ values [Eq. (14)]. The present results indicate that the distribution of $I_{\mathrm{c}} / I_{\mathrm{c} 0}$ values is governed by the difference in damage evolution among the specimens stemming from the distributed $\varepsilon_{\mathrm{f}}-\varepsilon_{\mathrm{r}}$ values.

\section{DISTRIBUTION OF IRREVERSIBLE BENDING STRAIN AND DISTRIBUTION OF CRITICAL CURRENT AT LOW BENDING STRAINS}

As shown in Fig. 8, model $\mathrm{R}$ is useful for describing the critical current-bending strain relation at high bending strains, but overestimates the irreversible bending strain and critical current values at low bending strains due to the simplification of the shape of the core. In this section, using model $\mathrm{S}$ with the actual shape of the core, we attempt to reveal the distribution of the irreversible bending strain and the critical current distribution at low bending strains.

\section{A. Distribution of irreversible bending strain}

The distribution function of $\varepsilon_{\mathrm{f}}-\varepsilon_{\mathrm{r}}$ values can be estimated only when all specimens are damaged. In the present work, $\varepsilon_{\mathrm{B}}=0.338 \%$ was the lowest bending strain at which all specimens were damaged and the distribution of the $\varepsilon_{\mathrm{f}}-\varepsilon_{\mathrm{r}}$ values could be estimated. For this reason, the distribution function of $\varepsilon_{\mathrm{f}}-\varepsilon_{\mathrm{r}}$ values at $\varepsilon_{\mathrm{B}}=0.338 \%$ was used as a first approximation for describing the distribution of $\varepsilon_{\mathrm{B} \text {,irr }}$ values. Substituting $\varepsilon_{\mathrm{f}}-\varepsilon_{\mathrm{r}}=\varepsilon_{\mathrm{B}, \text { irr }} y_{\text {core, max }}(\mathrm{S}) /(t / 2)$ derived from Eq. (3) into Eq. (9), we obtain the cumulative distribution function of $\varepsilon_{\mathrm{B}, \mathrm{ir}}$ as follows:

$$
F\left(\varepsilon_{\mathrm{B}, \mathrm{irr}}\right)=1-\exp \left[-\left\{\frac{\varepsilon_{\mathrm{B}, \text { irr }}-\frac{\left(\varepsilon_{\mathrm{f}}-\varepsilon_{\mathrm{r}}\right)_{\min }}{y_{\text {core, } \max }(\mathrm{S}) /(t / 2)}}{\frac{\left(\varepsilon_{\mathrm{f}}-\varepsilon_{\mathrm{r}}\right)_{0}}{y_{\text {core, } \max }(\mathrm{S}) /(t / 2)}}\right\}^{m}\right] .
$$

Substituting $\left(\varepsilon_{\mathrm{f}}-\varepsilon_{\mathrm{r}}\right)_{\min }=0.130 \%, m=4.19$, and $\left(\varepsilon_{\mathrm{f}}-\varepsilon_{\mathrm{r}}\right)_{0}$ $=0.0928 \%$ obtained from the result at $\varepsilon_{\mathrm{B}}=0.338 \%$, $y_{\text {core, } \max }(\mathrm{S})=0.101 \mathrm{~mm}$, and $t=0.230 \mathrm{~mm}$ into Eq. (20), we calculated the cumulative distribution of $\varepsilon_{\mathrm{B} \text {,irr }}$ as shown in Fig. 10. When many specimens are tested, the specimen with the lowest $\varepsilon_{\mathrm{f}}-\varepsilon_{\mathrm{r}}$ value $\left[\left(\varepsilon_{\mathrm{f}}-\varepsilon_{\mathrm{r}}\right)_{\min }=0.13 \%\right]$ at $y_{\text {core,max }}(\mathrm{S})$ is damaged first when $\varepsilon_{\mathrm{B}}$ reaches its $\varepsilon_{\mathrm{B} \text {,irr }}$ value $\left[\varepsilon_{\mathrm{B}, \text { irr,min }}=\left(\varepsilon_{\mathrm{f}}\right.\right.$ $\left.-\varepsilon_{\mathrm{r}}\right)_{\min }(t / 2) / y_{\text {core,max }}(\mathrm{S})$, Eq. (3)]. The number of damaged specimens increases with increasing $\varepsilon_{\mathrm{B}}$, in accordance with the increase in $F\left(\varepsilon_{\mathrm{B}, \mathrm{irr}}\right)$. At $\varepsilon_{\mathrm{B}}$, the specimens whose $\varepsilon_{\mathrm{B} \text {,irr }}$ 


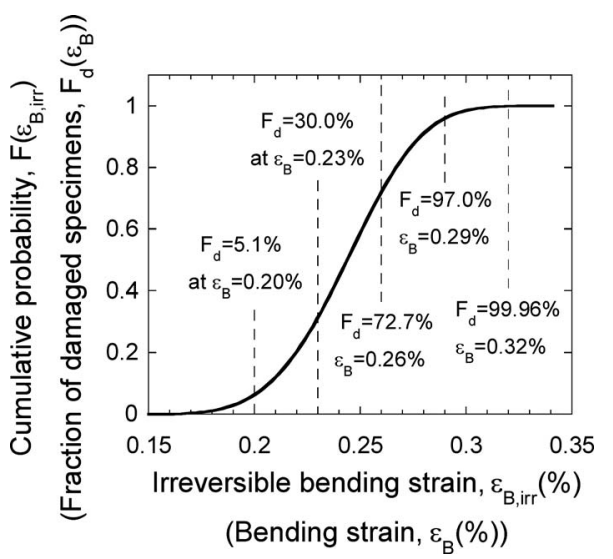

FIG. 10. Variation of cumulative probability $F\left(\varepsilon_{\mathrm{B}, \text { irr }}\right)$ with irreversible bending strain $\varepsilon_{\mathrm{B}, \text { irr }}$, which corresponds to change in fraction $F_{\mathrm{d}}$ (=ratio of the number of damaged specimens to that of all specimens) with bending strain $\varepsilon_{\mathrm{B}} . F_{\mathrm{d}}$ values at representative bending strains are noted for reference.

values are lower than $\varepsilon_{\mathrm{B}}$ have been damaged. The fraction of the damaged specimens $F_{\mathrm{d}}$ (=ratio of the number of damaged specimens to that of all specimens) at $\varepsilon_{\mathrm{B}}$ is calculated by replacing $\varepsilon_{\mathrm{B} \text {,irr }}$ with $\varepsilon_{\mathrm{B}}$ in Eq. (20). Accordingly, as shown in Fig. 10, the fractions of the damaged specimens $F_{\mathrm{d}}$ were found to be $5.1 \%, 30.0 \%, 72.7 \%, 97.0 \%, 99.96 \%$, and $100 \%$ at $\varepsilon_{\mathrm{B}}=0.20 \%, 0.23 \%, 0.26 \%, 0.29 \%, 0.32 \%$, and $0.35 \%$, respectively. The distribution of $I_{\mathrm{c}} / I_{\mathrm{c} 0}$ for the bending strain range $0 \%-0.35 \%$ was calculated as shown below. This range covers regions in which no specimen is damaged $\left(\varepsilon_{\mathrm{B}}\right.$ $=0 \%-0.15 \%)$, damaged and nondamaged specimens coexist $(0.15 \%-0.32 \%)$, and almost all specimens are damaged $(0.32 \%-0.35 \%)$.

\section{B. Variation of distribution of critical current with bending strain at low bending strain range}

Due to the distributed $\varepsilon_{B, \text { irr }}$ values, some specimens have higher $\varepsilon_{\mathrm{B} \text {,irr }}$ values than $\varepsilon_{\mathrm{B}}$ but the others do not. Accordingly, at a given $\varepsilon_{\mathrm{B}}$, the specimens with $\varepsilon_{\mathrm{B} \text {,irr }}$ values higher than $\varepsilon_{\mathrm{B}}$ are not damaged and retain the original critical current $I_{\mathrm{c}} / I_{\mathrm{c} 0}=1$ (unity), while those with $\varepsilon_{\mathrm{B} \text {,irr }}$ values lower than $\varepsilon_{\mathrm{B}}$ are damaged and their critical current is reduced from 1 (unity). Under such conditions, the distribution of $I_{\mathrm{c}} / I_{\mathrm{c} 0}$ was calculated with Eq. (5) and the distribution function of $\varepsilon_{\mathrm{f}}-\varepsilon_{\mathrm{r}}$ obtained at $\varepsilon_{\mathrm{B}}=0.338 \%$.

Figures 11 and 12 show the calculated variation of cumulative probability $F\left(I_{\mathrm{c}} / I_{\mathrm{c} 0}\right)$ and probability density $f\left(I_{\mathrm{c}} / I_{\mathrm{c} 0}\right)$ with increasing $\varepsilon_{\mathrm{B}}$ from $0 \%$ to $0.35 \%$. In Fig. 12, the distribution of $I_{\mathrm{c}} / I_{\mathrm{c} 0}$ was calculated in steps of 0.02 . Accordingly, the density $f$ at $I_{\mathrm{c}} / I_{\mathrm{c} 0}=0.98$, for example, includes the contribution of the damaged specimens with $I_{\mathrm{c}} / I_{\mathrm{c} 0}$ values from 0.97 to 0.99 . The density of $\mathrm{f}$ at $I_{\mathrm{c}} / I_{\mathrm{c} 0}=1$ includes the contribution of nondamaged specimens with $I_{\mathrm{c}} / I_{\mathrm{c} 0}=1$ and damaged specimens with $I_{\mathrm{c}} / I_{\mathrm{c} 0}$ from 0.99 to 1 .

As $\left(\varepsilon_{\mathrm{f}}-\varepsilon_{\mathrm{r}}\right)_{\min }$ was $0.130 \%$, the minimum $\varepsilon_{\mathrm{B}, \mathrm{irr}}, \varepsilon_{\mathrm{B}, \mathrm{irr}, \min }$ was calculated to be $0.148 \%$ [Eq. (3)]. If we use the average of $\varepsilon_{\mathrm{f}}-\varepsilon_{\mathrm{r}}$ values, $\left(\varepsilon_{\mathrm{f}}-\varepsilon_{\mathrm{r}}\right)_{\mathrm{av}}=0.214 \%$, the average irreversible strain $\varepsilon_{\mathrm{B} \text {,irr,av }}$ is calculated to be $0.243 \%$ with Eq. (3), which is around $0.1 \%$ higher than $\varepsilon_{\mathrm{B}, \mathrm{irr}, \min }(0.148 \%)$. As shown by

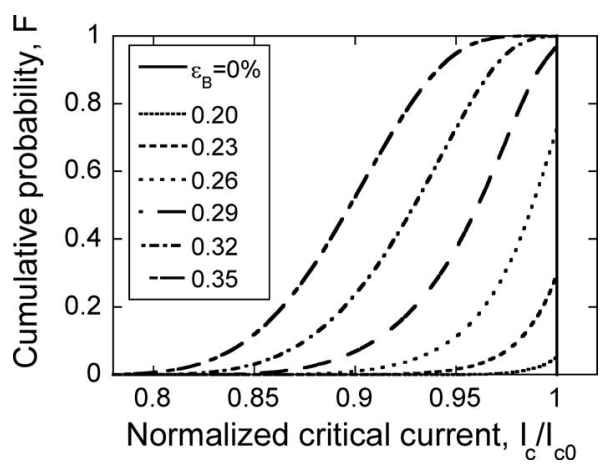

FIG. 11. Calculated variation of cumulative probability $F\left(I_{\mathrm{c}} / I_{\mathrm{c} 0}\right)$ of normalized critical current with bending strain $\varepsilon_{\mathrm{B}}$ in transitional bending strain range where fraction of damaged specimens increase from 0 to 1 (unity).

this difference, when many specimens with different $\varepsilon_{\mathrm{f}}-\varepsilon_{\mathrm{r}}$ values are tested, there are some specimens with very low irreversible bending strain.

As shown above, due to the distributed nature of $\varepsilon_{\mathrm{f}}-\varepsilon_{\mathrm{r}}$ values, $\varepsilon_{\mathrm{B} \text {,irr }}$ is also distributed and thus the damaged and nondamaged specimens coexist at $\varepsilon_{\mathrm{B}}=0.15 \%-0.32 \%$. At
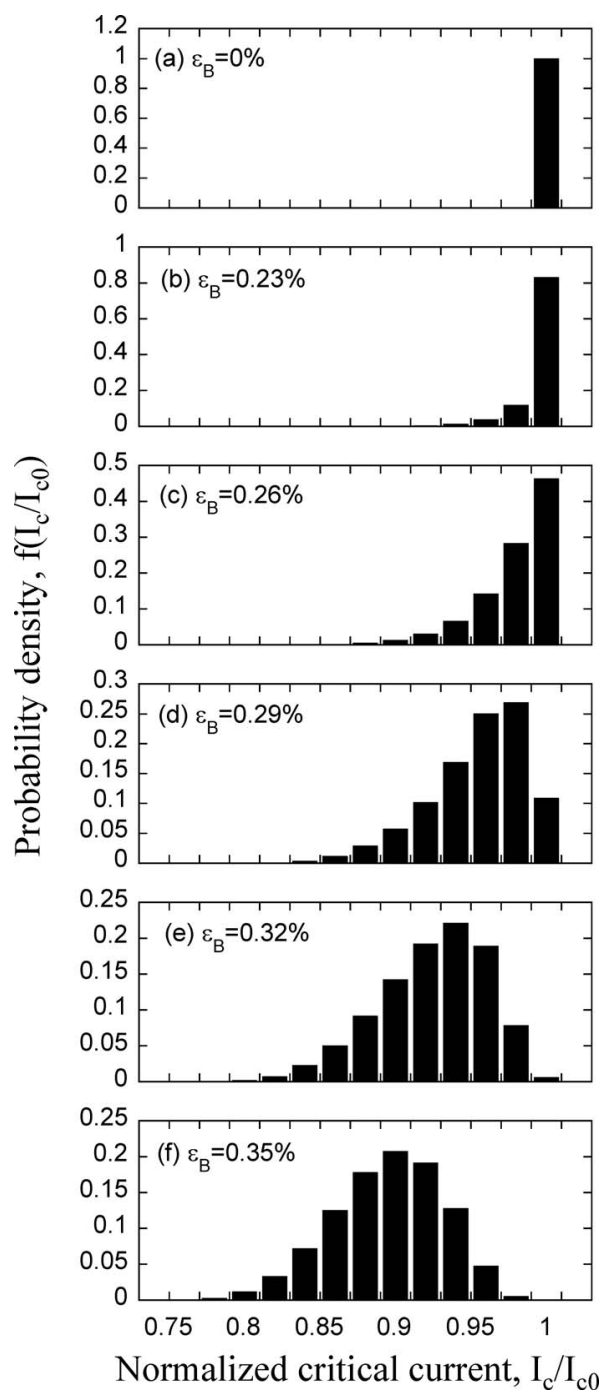

FIG. 12. Calculated variation of probability density $f\left(I_{\mathrm{c}} / I_{\mathrm{c} 0}\right)$ of critical current with bending strain, obtained from cumulative probability-critical current relation in Fig. 11 

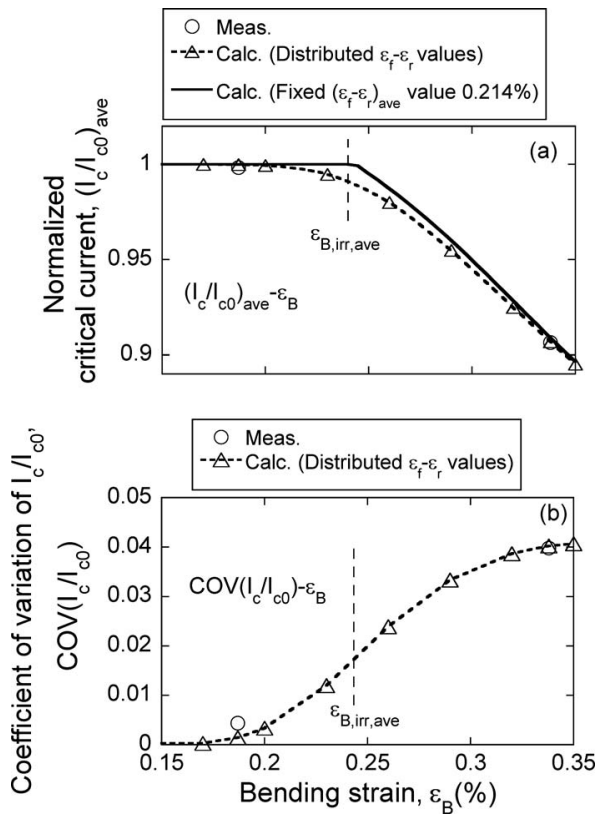

FIG. 13. Calculated variation of $\left(I_{\mathrm{c}} / I_{\mathrm{c} 0}\right)_{\mathrm{av}}$ and $\operatorname{COV}\left(I_{\mathrm{c}} / I_{\mathrm{c} 0}\right)$ with bending strain $\varepsilon_{\mathrm{B}}$ including transitional bending strain range where fraction of damaged specimens increases from 0 to 1 (unity).

$\varepsilon_{\mathrm{B}}=\varepsilon_{\mathrm{B}, \mathrm{irr}, \mathrm{av}}=0.243 \%$, around $50 \%$ of the specimens are damaged (Fig. 10). If we use a unique value of $\varepsilon_{\mathrm{B}, \text { irr,av }}(=0.243 \%)$ for the calculation, $\left(I_{\mathrm{c}} / I_{\mathrm{c} 0}\right)_{\mathrm{av}}$ is 1 (unity) up to $\varepsilon_{\mathrm{B}}=0.243 \%$. In such a case, the influence of the existence of around $50 \%$ damaged specimens on the average critical current at $\varepsilon_{\mathrm{B}}=0.243 \%$ is not included. For comparison, the variation of $\left(I_{\mathrm{c}} / I_{\mathrm{c} 0}\right)_{\mathrm{av}}$ with $\varepsilon_{\mathrm{B}}$ was calculated both for a fixed value of $\left(\varepsilon_{\mathrm{f}}-\varepsilon_{\mathrm{r}}\right)_{\mathrm{av}}=0.214 \%$ (corresponding to $\varepsilon_{\mathrm{B}, \mathrm{irr}, \mathrm{av}}$ $=0.243 \%$ ) and distributed $\varepsilon_{\mathrm{f}}-\varepsilon_{\mathrm{r}}$ values (corresponding to distributed $\varepsilon_{\mathrm{B}, \text { irr }}$ values from around $0.15 \%$ to $0.32 \%$, with $\varepsilon_{\mathrm{B}, \text { irr,av }}=0.243 \%$ ). For reference, the change in the COV of the $I_{\mathrm{c}} / I_{\mathrm{c} 0}$ values with bending strain $\varepsilon_{\mathrm{B}}$ was also calculated using the distributed $\varepsilon_{\mathrm{f}}-\varepsilon_{\mathrm{r}}$ values.

The variation of $\left(I_{\mathrm{c}} / I_{\mathrm{c} 0}\right)_{\mathrm{av}}$ with $\varepsilon_{\mathrm{B}}$ is shown in Fig. 13(a). The solid and broken curves denote the calculation results for a fixed value of $\left(\varepsilon_{\mathrm{f}}-\varepsilon_{\mathrm{r}}\right)_{\mathrm{av}}=0.214 \%$ and for distributed $\varepsilon_{\mathrm{f}}-\varepsilon_{\mathrm{r}}$ values, respectively. The open triangles show the calculated $\left(I_{\mathrm{c}} / I_{\mathrm{c} 0}\right)_{\mathrm{av}}$ values and open circles at $\varepsilon_{\mathrm{B}}=0.187 \%$ and $0.338 \%$ show the measured values. The variation in the COV of the $I_{\mathrm{c}} / I_{\mathrm{c} 0}$ values, $\operatorname{COV}\left(I_{\mathrm{c}} / I_{\mathrm{c} 0}\right)$, with $\varepsilon_{\mathrm{B}}$ for distributed $\varepsilon_{\mathrm{f}}$ $-\varepsilon_{\mathrm{r}}$ values is shown in Fig. 13(b). The measured values of $\left(I_{\mathrm{c}} / I_{\mathrm{c} 0}\right)_{\mathrm{av}}$ and $\operatorname{COV}\left(I_{\mathrm{c}} / I_{\mathrm{c} 0}\right)$ at $\varepsilon_{\mathrm{B}}=0.187 \%$ and $0.338 \%$ are reproduced well. The following features are inferred from Figs. 10-13.

(1) Taking the result at $\varepsilon_{\mathrm{B}}=0.23 \%$ as a representative example, the fraction $F_{\mathrm{d}}$ of damaged specimens was $30 \%$ (Fig. 10). $I_{\mathrm{c}} / I_{\mathrm{c} 0}$ of the damaged specimens ranged from $0.87=\left(I_{\mathrm{c}} / I_{\mathrm{c} 0}\right)_{\min }$ to 1.0 (Fig. 11), and $70 \%$ of the specimens retained the original critical current $\left(I_{\mathrm{c}} / I_{\mathrm{c} 0}=1\right)$, due to which the cumulative probability $F\left(I_{\mathrm{c}} / I_{\mathrm{c} 0}\right)$ increased from 0.30 to 1 at $I_{\mathrm{c}} / I_{\mathrm{c} 0}=1$ (Fig. 11). When $\varepsilon_{\mathrm{B}}$ was raised from $0.23 \%$ to $0.26 \%, F_{\mathrm{d}}$ increased to $73 \%$ (Fig. 10). $I_{\mathrm{c}} / I_{\mathrm{c} 0}$ of the damaged specimens ranged from 0.83 to 1.0 (Fig. 11), and $27 \%$ of the specimens retained the original critical current $\left(I_{\mathrm{c}} / I_{\mathrm{c} 0}=1\right)$, due to which $F\left(I_{\mathrm{c}} / I_{\mathrm{c} 0}\right)$ increased from 0.73 to 1 at $I_{\mathrm{c}} / I_{\mathrm{c} 0}=1$ (Fig. 11). In this way, the minimum critical current decreased and the width of the distribution of $I_{\mathrm{c}} / I_{\mathrm{c} 0}$ increased with increasing $\varepsilon_{\mathrm{B}}$. The increase in the width of the distribution of $I_{\mathrm{c}} / I_{\mathrm{c} 0}$ value is reflected by the tail in the low $I_{\mathrm{c}} / I_{\mathrm{c} 0}$ region in the $f-I_{\mathrm{c}} / I_{\mathrm{c} 0}$ diagram (Fig. 12).

(2) The $\left(I_{\mathrm{c}} / I_{\mathrm{c} 0}\right)_{\mathrm{av}}$ values at $\varepsilon_{\mathrm{B}}=0.23 \%, 0.26 \%$, and $0.29 \%$ were calculated to be $0.995,0.980$, and 0.955 [Fig. 13(a)], while the fractions of damaged specimens were as high as $30 \%, 73 \%$, and $96 \%$, respectively (Fig. 10). This signifies that, while the fraction of damaged specimens was high, the reduction in the $I_{\mathrm{c}} / I_{\mathrm{c} 0}$ value of each specimen was small on average and the tail in the low $I_{\mathrm{c}} / I_{\mathrm{c} 0}$ range in the $f-I_{\mathrm{c}} / I_{\mathrm{c} 0}$ diagram was caused by a small number of the seriously damaged specimens.

(3) $\left(I_{\mathrm{c}} / I_{\mathrm{c} 0}\right)_{\mathrm{av}}$ started to decrease at $\varepsilon_{\mathrm{B}}$ lower than $\varepsilon_{\mathrm{B} \text {,irr,av }}$ [Fig. 13(a)] due to the existence of specimens with lower $\varepsilon_{\mathrm{B} \text {,irr }}$ values than $\varepsilon_{\mathrm{B} \text {,irr,av }}$ (Fig. 10). Accordingly, the $\left(I_{\mathrm{c}} / I_{\mathrm{c} 0}\right)_{\mathrm{av}}-\varepsilon_{\mathrm{B}}$ curves calculated with the distributed $\varepsilon_{\mathrm{f}}-\varepsilon_{\mathrm{r}}$ values for $\varepsilon_{\mathrm{B}}=0.2 \%-0.3 \%$ were lower than the curve calculated with a fixed value of $\left(\varepsilon_{\mathrm{f}}-\varepsilon_{\mathrm{r}}\right)_{\mathrm{av}}$ $=0.214 \%$ [Fig. 13(a)]. Beyond 0.3\%, where almost all specimens were damaged (Fig. 10), the $\left(I_{\mathrm{c}} / I_{\mathrm{c} 0}\right)_{\mathrm{av}}$ values calculated with distributed $\varepsilon_{\mathrm{f}}-\varepsilon_{\mathrm{r}}$ values were very close to those calculated with a fixed value of $\left(\varepsilon_{\mathrm{f}}-\varepsilon_{\mathrm{r}}\right)_{\mathrm{av}}$ $=0.214 \%$ [Fig. 13(a)].

(4) As shown in Fig. 3, $\operatorname{COV}\left(I_{\mathrm{c}} / I_{\mathrm{c} 0}\right)$ was 1 (unity) at $\varepsilon_{\mathrm{B}}$ $=0 \%$. This increased largely when $\varepsilon_{\mathrm{B}}$ was raised from $0.187 \%$ to $0.338 \%$. Such a feature is well reproduced by the calculated variation of $\operatorname{COV}\left(I_{\mathrm{c}} / I_{\mathrm{c} 0}\right)$ in the bending strain range $0.15 \%-0.35 \%$ [Fig. 13(b)]. In accordance with the decrease in $\left(I_{\mathrm{c}} / I_{\mathrm{c} 0}\right)_{\mathrm{av}}$ with $\varepsilon_{\mathrm{B}}, \operatorname{COV}\left(I_{\mathrm{c}} / I_{\mathrm{c} 0}\right)$ increased with $\varepsilon_{\mathrm{B}}$. The increase in $\operatorname{COV}\left(I_{\mathrm{c}} / I_{\mathrm{c} 0}\right)$ started at $\varepsilon_{\mathrm{B}}$ lower than $\varepsilon_{\mathrm{B} \text {,irr,av }}$ and increased largely with $\varepsilon_{\mathrm{B}}$ in the range $\varepsilon_{\mathrm{B}}=0.15 \%-0.35 \%$ where the fraction of the damaged specimens increased from almost zero to unity.

\section{CONCLUSIONS}

The measured distributions of $I_{\mathrm{c}} / I_{\mathrm{c} 0}$ values varying with bending strain were well described by the modeling approach in which the relation between the heterogeneous damage evolution and the distribution of $I_{\mathrm{c}} / I_{\mathrm{c} 0}$ values was expressed by using the distribution of the $\varepsilon_{\mathrm{f}}-\varepsilon_{\mathrm{r}}$ values, shape of the core, and bending strain.

The $I_{\mathrm{c}} / I_{\mathrm{c} 0}$ values, measured at bending strains where all specimens were damaged, were described by the threeparameter Weibull distribution function. The reason for this was clarified through the derivation of the three-parameter Weibull distribution from the relation between the distribution of the $\varepsilon_{\mathrm{f}}-\varepsilon_{\mathrm{r}}$ values and the distribution of $I_{\mathrm{c}} / I_{\mathrm{c} 0}$ values.

Due to the distributed nature of $\varepsilon_{\mathrm{f}}-\varepsilon_{\mathrm{r}}$ values, the irreversible bending strain was also distributed, which was described by the three-parameter Weibull distribution function. The analytical study of the distribution of the critical current near the average irreversible bending strain revealed the following features: (i) In the transition bending strain range where the fraction of damaged specimens increases, the av- 
erage critical current for distributed $\varepsilon_{\mathrm{f}}-\varepsilon_{\mathrm{r}}$ values is lower than the prediction based on a fixed average $\varepsilon_{\mathrm{f}}-\varepsilon_{\mathrm{r}}$ value, and (ii) in such a transition bending strain range, the COV of the critical current values increases largely with increasing bending strain.

\section{ACKNOWLEDGMENTS}

The present work was supported by a Grant-in-Aid from the Ministry of Education, Culture, Sports, Science and Technology, Japan (Grant No. 18106011).

${ }^{1}$ P. Vase, R. Flükiger, M. Leghissa, and B. Glowacki, Supercond. Sci. Technol. 13, R71 (2000).

${ }^{2}$ H. J. N. van Eck, K. Vargast, B. ten Haken, and H. H. J. ten Kate, Supercond. Sci. Technol. 15, 1213 (2002).

${ }^{3}$ H. Kitaguchi, K. Itoh, H. Kumakura, T. Takeuchi, K. Togano, and H. Wada, IEEE Trans. Appl. Supercond. 11, 3058 (2001).

${ }^{4}$ S. Ochiai, N. Miyazaki, D. Doko, T. Nagai, M. Nakamura, H. Okuda, S. S. Oh, M. Hojo, M. Tanaka, and K. Osamura, J. Nucl. Mater. 329, 1585 (2004).

${ }^{5}$ S. Ochiai, T. Matsuoka, J. K. Shin, H. Okuda, M. Sugano, M. Hojo, and K. Osamura, Supercond. Sci. Technol. 20, 1076 (2007).

${ }^{6}$ D. C. van der Laan, H. J. N. van Eck, B. ten Haken, H. H. J. ten Kate, and J. Schwartz, IEEE Trans. Appl. Supercond. 13, 3534 (2003).

${ }^{7}$ H. W. Weijers, J. Schwartz, and B. ten Haken, Physica C 372, 1364 (2002).

${ }^{8}$ H. J. N. van Eck, D. C. van der Laan, M. Dhallé, B. ten Haken, and H. H J. ten Kate, Supercond. Sci. Technol. 16, 1026 (2003).

${ }^{9}$ S. Ochiai, T. Ishida, D. Doko, K. Morishita, H. Okuda, S. S. Oh, D. W. Ha, M. Hojo, M. Tanaka, M. Sugano, and K. Osamura, Supercond. Sci. Technol. 18, S232 (2005).

${ }^{10}$ H. S. Shin and K. Katagiri, Supercond. Sci. Technol. 16, 1012 (2003).
${ }^{11}$ S. Ochiai, J. K. Shin, S. Iwamoto, H. Okuda, S. S. Oh, D. W. Ha, and M. Sato, J. Appl. Phys. 103, 123911 (2008).

${ }^{12}$ S. Ochiai, J. K. Shin, H. Okuda, M. Sugano, M. Hojo, K. Osamura, T. Kuroda, K. Itoh, and H. Wada, Supercond. Sci. Technol. 21, 054002 (2008).

${ }^{13}$ S. Ochiai, M. Fujimoto, H. Okuda, S. S. Oh, and D. W. Ha, Supercond. Sci. Technol. 20, 800 (2007)

${ }^{14}$ K. Katagiri, H. S. Shin, K. Kasaba, T. Tsukinokizawa, K. Hiroi, T. Kuroda,

K. Itoh, and H. Wada, Supercond. Sci. Technol. 16, 995 (2003).

${ }^{15}$ T. Kuroda, K. Itoh, K. Katagiri, W. Goldacker, W. Hsessler, B. ten Haken, M. Kiuchi, N. Noto, S. Ochiai, S. Otabe, H. S. Shin, J. Sosnowski, H. Weijers, H. Wada, and K. Kumakura, Physica C 425, 111 (2005).

${ }^{16}$ S. Ochiai, M. Fujimoto, H. Okuda, S. S. Oh, and D. W. Ha, J. Appl. Phys. 105, 063912 (2009).

${ }^{17}$ A. L. Mbaruku and J. Schwartz, J. Appl. Phys. 101, 073913 (2007).

${ }^{18}$ Y. Wang, Y. Lu, X. Xu, S. Dai, D. Hui, L. Xiao, and L. Lin, Cryogenics 47, 225 (2007).

${ }^{19}$ Y. Wang, S. Dai, X. Zhao, L. Xiao, L. Lin, and D. Hui, Supercond. Sci. Technol. 19, 1278 (2006).

${ }^{20}$ D. C. Larbalestier, X. Y. Cai, Y. Feng, H. Edelman, A. Umezawa, G. N. Riley, Jr., and W. L. Carter, Physica C 221, 299 (1994).

${ }^{21}$ M. D. Bentzon and P. Vase, IEEE Trans. Appl. Supercond. 9, 1594 (1999).

${ }^{22}$ M. Fee, S. Fleshler, A. Otto, and A. P. Malozemoff, IEEE Trans. Appl. Supercond. 11, 3337 (2001).

${ }^{23}$ B. ten Haken, R. A. M. Budde, and H. H. J. ten Kate, IEEE Trans. Appl. Supercond. 9, 1606 (1999).

${ }^{24}$ J. Paasi, T. Kalliohaka, A. Korpela, L. Soderlund, P. F. Hermann, J. Kvitkovic, and M. Majoros, IEEE Trans. Appl. Supercond. 9, 1598 (1999)

${ }^{25}$ W. Weibull, J. Appl. Mech. 28, 293 (1951).

${ }^{26}$ F. Irie, Y. Tsujioka, and T. Chiba, Supercond. Sci. Technol. 5, S379 (1992).

${ }^{27}$ T. Kiss, T. Matsushita, and F. Irie, Supercond. Sci. Technol. 12, 1079 (1999).

${ }^{28}$ M. Ahoranta, J. Lehtonen, P. Kováè, I. Hušek, and T. Melišek, Physica C 401, 241 (2004).

${ }^{29}$ K. Ogawa and K. Osamura, Phys. Rev. B 67, 184509 (2003). 